\title{
Lipid Nanoparticles as Carriers for RNAi against Viral Infections: Current Status and Future Perspectives
}

\author{
Josune Torrecilla, Alicia Rodríguez-Gascón, \\ María Ángeles Solinís, and Ana del Pozo-Rodríguez
}

Pharmacokinetic, Nanotechnology and Gene Therapy Group (PharmaNanoGene), Faculty of Pharmacy, Centro de Investigación Lascaray Ikergunea, University of the Basque Country UPV/EHU, Paseo de la Universidad 7, 01006 Vitoria-Gasteiz, Spain

Correspondence should be addressed to Ana del Pozo-Rodríguez; ana.delpozo@ehu.es

Received 25 February 2014; Revised 14 July 2014; Accepted 14 July 2014; Published 12 August 2014

Academic Editor: Kamla Pathak

Copyright (C) 2014 Josune Torrecilla et al. This is an open access article distributed under the Creative Commons Attribution License, which permits unrestricted use, distribution, and reproduction in any medium, provided the original work is properly cited.

\begin{abstract}
The efforts made to develop RNAi-based therapies have led to productive research in the field of infections in humans, such as hepatitis C virus (HCV), hepatitis B virus (HBV), human immunodeficiency virus (HIV), human cytomegalovirus (HCMV), herpetic keratitis, human papillomavirus, or influenza virus. Naked RNAi molecules are rapidly digested by nucleases in the serum, and due to their negative surface charge, entry into the cell cytoplasm is also hampered, which makes necessary the use of delivery systems to exploit the full potential of RNAi therapeutics. Lipid nanoparticles (LNP) represent one of the most widely used delivery systems for in vivo application of RNAi due to their relative safety and simplicity of production, joint with the enhanced payload and protection of encapsulated RNAs. Moreover, LNP may be functionalized to reach target cells, and they may be used to combine RNAi molecules with conventional drug substances to reduce resistance or improve efficiency. This review features the current application of LNP in RNAi mediated therapy against viral infections and aims to explore possible future lines of action in this field.
\end{abstract}

\section{Introduction}

Gene therapy is a relatively recent approach in the management of human diseases and has resulted in an increasingly interest as therapeutic strategy. While traditional drug therapies involve the administration of therapeutic chemicals that have been synthesized outside the body, gene therapy tries to direct patient's cells to produce and deliver a therapeutic agent or to knock down the production of undesirable molecules. Gene therapy was first defined as the administration of genetic material into a human patient with the intent of correcting a specific genetic defect [1]. This definition appeared in the first gene therapy protocols in the early 90s, related to trials that aimed to correct the effects of some monogenic recessive diseases. Nowadays, the European Agency of Medicines (EMA) defines gene therapy as biological medicinal products which fulfils the following two characteristics: (a) the active substance contains or consists of a recombinant nucleic acid applied to human beings in order to regulate, repair, replace, add, or delete a genetic sequence; (b) its beneficial effect relates directly to the recombinant nucleic acid sequence it contains or to the result of genetic expression of this sequence [2].

Since the first FDA-approved gene therapy experiment in $1990[3,4]$, more than 1900 clinical trials have been performed using a number of techniques for gene therapy up to January 2014 [5]. Table 1 collects the indications addressed by gene therapy clinical trials and the number of events related to each indication. As observed in this table, infectious diseases are in the third place in the ranking, with a percentage with respect to total approved clinical trials similar to that of monogenic diseases or cardiovascular diseases.

Nucleic acid-based therapy has been traditionally focused on the use of DNA as the active substance, but since the discovery of the RNA interference (RNAi) pathway [6], RNA has also gained great interest. Among the multiple possible applications of the RNAi-based therapy, numerous studies have demonstrated its potential in the control and treatment 
TABLE 1: Indications addressed by gene therapy clinical trials up to January 2014.

\begin{tabular}{lccc}
\hline Ranking & Indication & Number of trials $(n)$ & Percentage with respect to total gene therapy clinical trials (\%) \\
\hline 1 & Cancer diseases & 1274 & 63.8 \\
2 & Monogenic diseases & 178 & 8.9 \\
3 & Infectious diseases & 164 & 8.2 \\
4 & Cardiovascular diseases & 162 & 8.1 \\
5 & Healthy volunteers & 52 & 2.6 \\
6 & Gene marking & 50 & 2.5 \\
7 & Neurological diseases & 37 & 1.9 \\
8 & Other diseases & 35 & 1.8 \\
9 & Ocular diseases & 31 & 1.6 \\
10 & Inflammatory diseases & 13 & 0.7 \\
\hline
\end{tabular}

of different viral infections in humans, such as hepatitis $\mathrm{C}$ virus (HCV), hepatitis $\mathrm{B}$ virus (HBV), human immunodeficiency virus (HIV), human cytomegalovirus (HCMV), herpetic keratitis, human papillomavirus, or influenza virus [7-13].

A key challenge to exploit the full potential of RNAi therapeutics is their efficient delivery to the target cells. On the one hand, naked RNAi molecules are rapidly digested by nucleases in the serum after systemic administration; on the other hand, due to the negative surface charge of RNA, the entry into the cell cytoplasm is hampered. A number of techniques have been attempted to overcome these problems: physical methods such as electroporation or hydrodynamic injection [14, 15], viral vectors [16], or lipid and polymeric nanoparticles [17, 18]. Among them, lipid nanoparticles (LNP) represent one of the most widely studied delivery systems for in vivo application of RNAi $[19,20]$. The aim of this review is to collect the state of the art and the future perspectives of the utility LNP as RNAi vectors for human viral infections.

\section{RNA Interference (RNAi)}

RNAi is a naturally occurring process of gene regulation present in plants and mammalian cells. The first evidence of the existence of this mechanism appeared in 1998, when Fire et al. [6] observed in Caenorhabditis elegans that doublestranded RNAs (dsRNAs) were the basis of sequence-specific inhibition of protein expression. Subsequent works demonstrated that the molecules that induced RNAi were short dsRNAs, of 21 nucleotides in length, called short interfering RNAs (siRNAs), and that siRNAs were able to start the RNAi process in mammalian cells [21]. The RNAi response is activated when the dsRNA is processed by a ribonuclease III-like enzyme called Dicer, resulting in the formation of a siRNA. The siRNA is incorporated into the RNA induced silencing complex (RISC), where a helicase unwinds the duplex siRNA. The resulting antisense strand guides the RISC to its complementary mRNA, which will be cleaved [22]. Typically, there are three different types of commonly used RNAi molecules: siRNA, short-hairpin RNA (shRNA, also named expressed RNAi activators), or microRNA (miRNA). siRNAs, as mentioned before, are dsRNA molecules of about
19-23 base pair nucleotides in length, able to mediate sitespecific cleavage and destruction of the targeted mRNA [23]. shRNAs consist of two complementary 19-22 bp RNA sequences linked by a short loop of 4-11. These RNAs are synthesized within the cell by DNA vector-mediated production [24]. shRNAs can be transcribed through either RNA polymerase II or III. The first transcript generates a hairpin like stem-loop structure and then is processed in the nucleus by a complex containing the RNase II enzyme Drosha. The individual pre-shRNAs generated are finally transported to the cytoplasm by exportin 5 . Once in the cytoplasm, the complex Dicer processes the loop of the hairpin to form a double-stranded siRNA. shRNAs represent an important tool in the assessment of gene function in mammals and are largely used as a research tool. miRNAs are single stranded RNAs of about 20-24 nucleotides. This kind of RNAs acts as endogenous posttranscriptional repressors to downregulate gene expression [25]. miRNAs are transcribed from DNA as primary miRNA (pri-miRNA); in this case, primiRNAs are processed into precursor miRNA (pre-miRNA) by two proteins: Drosha and Pasha. Pre-miRNAs are then transported to the cytoplasm, and after processing by Dicer and unwinding to obtain the miRNA, the following steps are identical to those that occur with siRNA and shRNA as it is illustrated in Figure 1. Recent observations have shown that both miRNAs and siRNAs can suppress translation of mRNAs (in the case of an imperfect match) and can cleave target RNAs (in the case of a perfect match) and play a decisive role in gene and genome regulation [26]. It has been also observed that shRNA can act via miRNA- or siRNA-like mechanism. It is believed that the miRNA-like mechanism is faster than siRNA-like mechanism, because the latter acts via perfect complementarity for a target message [27].

The main advantage of synthesized siRNAs is that these molecules do not need to reach the nucleus to exert effect. However, modifications are necessary to increase their stability, resulting in some cases in loss of siRNA function [28]; there must be a balance between stability and efficacy when modifications are introduced in siRNA. When miRNAs or shRNA expression plasmids are used, they must initially reach the nucleus of cells to be processed. The resulting molecules are then transported to the cytoplasm and finally incorporated into the RISC for activity. Therefore, a limitation 


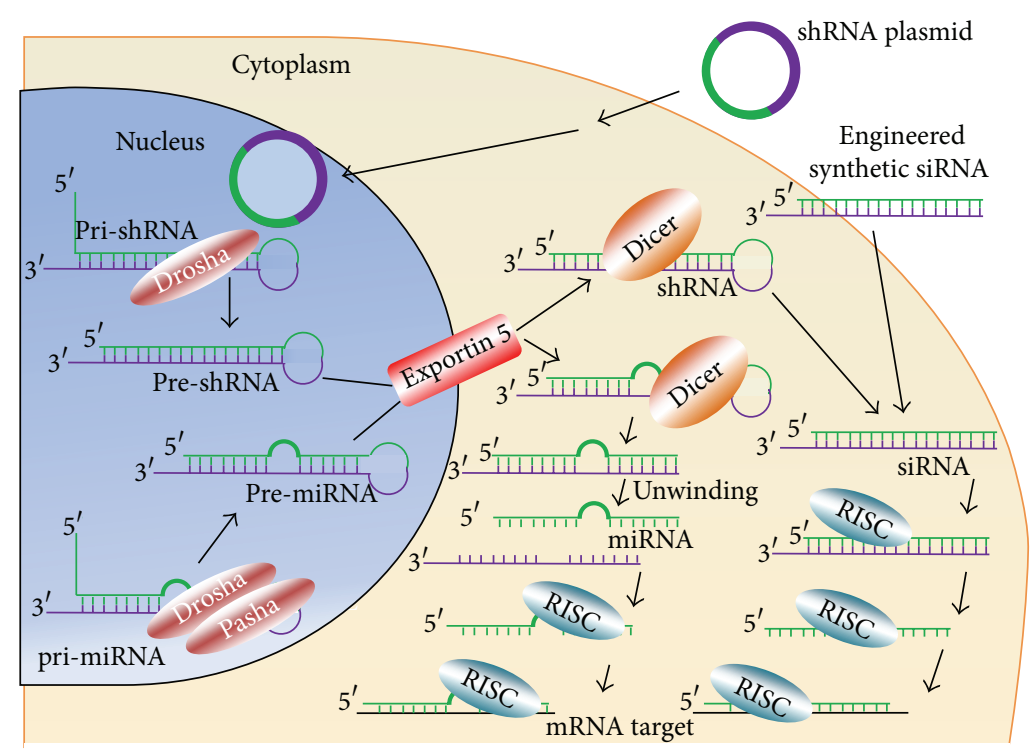

FIGURE 1: RNAi mechanism. Differences between siRNA, shRNA, and miRNA as therapeutic tools.

of miRNA and shRNA is the need to be delivered into the cell nucleus, although they have a greater durability and higher silencing capacity than siRNAs [29].

RNAi seems to play an important role in the antiviral defense mechanism in human cells, suggesting its potential use as therapeutic in human infectious diseases. For instance, HIV-1 shows higher replication capacity in cells that have suffered knockout of Dicer and Drosha expression [30]. In this sense, the mammalian stomatitis virus achieved increased accumulation in Caenorhabditis elegans with defective RNAi machinery [31]. It has been also observed that the interferon (IFN) pathway works in coordination with miRNA to control viral infections. IFN- $\beta$ can induce the expression of several cellular miRNAs that form almost perfect nucleotide base pair matches with the HCV genome. When these miRNAs are artificially introduced, the antiviral effects of IFN- $\beta$ in HCV are reproduced, and the IFN response is lost when they are experimentally removed [32].

As mentioned above, to take advantage of the potential of RNAi as antiviral therapy, effective delivery is essential; in this regard, lipid-based systems are being widely used as RNAidelivery vectors.

\section{Lipid Nanoparticles (LNP)}

Lipid-based systems have been increasingly recognized as one of the most promising delivery systems for RNAi. Lipid carriers may be available in solid, semisolid, or liquid state in the form of solid lipid nanoparticles, nanostructured lipid carriers, lipid drug conjugate nanoparticles, liposomes, or nanoemulsions. These lipid-based systems were initially designed to address some of the challenges of conventional drug delivery systems, such as the increase of bioavailability of poorly soluble drugs, among others. Nowadays, the application of LNP in other fields, such as gene therapy, has gained attraction.
RNAi-lipid-based nanocarriers are able to provide protection from serum nucleases and extended circulation, which results in a higher access to the target tissue [38]. Sometimes, targeting is achieved by surface modification of nanocarriers with specific ligands to target cell populations, such as mannan-modified nanoparticles to direct vectors to alveolar macrophages [39]. Once in the target tissue, the RNA-delivery system will be internalized by the target cell and, upon receptor-mediated endocytosis, will be able to escape from the endosomal compartment into the cell cytoplasm where RNA machinery is located, while avoiding lysosomal enzymes [40]. When these delivery systems are applied to the treatment of viral infections, multiadministration treatment modalities are possible for improved clinical outcomes [41]. Moreover, due to their biocompatibility and their ease of large-scale production, large batches with reproducible specifications are possible.

3.1. Solid Lipid Nanoparticles (SLNs). SLNs are considered to be one of the most effective lipid-based colloidal carriers. SLNs are in the submicron size range of $50-1000 \mathrm{~nm}$ and are composed of physiologically compatible lipids recognized as safe, which are in solid state at room temperature. They consist of a solid lipid core surrounded by a layer of surfactants in an aqueous dispersion, with multiple potential combinations of lipids and surfactants $[42,43]$. The interest on SLNs has led to the development of different types of production methods (i.e., high-pressure homogenization) successfully implemented in pharmaceutical industry. The SLNs obtained with these techniques show long-term stability and the possibility to be subjected to commercial sterilization and lyophilized procedures [44-46].

SLNs are used not only as conventional drug delivery systems but also as carriers for therapeutic peptides, proteins or antigens, and bioactive molecules. Mannosylated SLNs loaded with hepatitis B surface antigen (HBsAg) were 
subcutaneously administered in vivo in mice and sustained antibody titer was obtained; these results demonstrated the potential of SLNs as carriers for vaccine delivery against HBV [59].

As gene delivery systems, SLNs have been studied over the last years for a large number of diseases $[46,60,61]$ and different routes of administration [62]. Cationic lipids are used to prepare SLNs due to their positive surface charge that interacts electrostatically with the negative charge of the nucleic acids. Our research group has developed nonviral vectors based on cationic SLNs $[63,64]$ decorated with peptides $[65,66]$, dextran [60], oligochitosans [67], or hyaluronic acid [68] able to transfect several cell lines and tissues both in vitro and in vivo [69-71]. To date, vectors that were developed for DNA delivery are being applied for siRNA delivery. In spite of their different physicochemical properties and the need to be transported to different parts of the cell (plasmid DNA needs to be transported into nucleus for gene expression whereas siRNA reaches its target in the cytoplasm), a number of publications describe the use of SLNs for delivery of both DNA [39, 72-74] and RNAi mediated molecules [75-78] with successful results.

Focusing on RNAi delivery, Montana et al. [78] demonstrated the utility of cationic SLNs, produced by microemulsion using Compritol ATO 888 as matrix lipid, Pluronic F68 as tensioactive, and dimethyldioctadecylammonium bromide (DDAB) as cationic lipid, as RNA carriers. In another study [76], SLNs composed of cholesteryl ester, triglyceride, cholesterol, dioleoylphosphatidylethanolamine (DOPE), and 3beta- $\left[\mathrm{N}-\left(\mathrm{N}^{\prime}, \mathrm{N}^{\prime}\right.\right.$ dimethylaminoethane) carbamoyl]-cholesterol (DC-chol) were able to bind electrostatically siRNA conjugated with polyethylene glycol (PEG) (siRNA-PEG). When compared to polyethylenimine, a commonly used transfectant polymer, the SLN-based system showed similar gene silencing efficiency and very low cytotoxicity in PC3 (human prostate cancer cell line) and MDAMB435 (human breast cancer cell line) cells. In a later work, these SLNs containing a siRNA anti-c-Met (an oncogene overexpressed in a variety of carcinomas) were evaluated in vivo in a glioblastoma multiform mouse model. After intravenous administration to mice, the siRNA-PEG/SLN system specifically crossed the blood-brain barrier to the tumor site with no apparent systemic toxicity. Treatment significantly inhibited tumor growth in a dose dependent manner, and a downregulation of c-Met was observed [77].

3.2. Nanostructured Lipid Carriers (NLCs). NLCs are solid lipid core carriers in the nanometer range composed of a mixture of liquid and solid lipids that are spatially incompatible leading to special structures with improved drug encapsulation and release properties. NLCs were developed as a tool to overcome the drawbacks of SLNs and to increase the oral bioavailability of poorly soluble compounds [79-83].

The choice of the lipid is critical to ensure the stability of the drug [79], and the structure of the lipid core matrix determines the classification of NLCs. Imperfect NLCs are made by mixing small amounts of liquid lipid and fatty acids with different chain lengths as solid lipid. The imperfections that are generated in the lipid core due to the crystallization increase the drug load and reduce, although not completely, the drug expulsion $[84,85]$. Multiple NLCs are made by mixing solid lipids and an excess of liquid lipid, generating oily nanocompartments into the lipid matrix where the drug is well accommodated [44]. Finally, in structureless or also called amorphous NLCs, special liquids are used, and the expulsion of the drug is avoided due to the lack of crystallization [85].

The application of NLCs to the treatment and prevention of infectious diseases has been attempted in various studies focused on the development of new antimalarial treatments [86-88] or in the improvement of encapsulation of hydrophilic antiretroviral drugs [89-91]. Although there are few reports about the application of NLCs as RNAi delivery systems, they could be an interesting alternative in codelivery strategies with conventional drugs. For instance, Taratula et al. [92] have recently described a multifunctional NLC system to improve the efficacy of anticancer drugs in lungs. The system was composed of an anticancer drug (doxorubicin or paclitaxel), joint with siRNA to avoid cellular resistance (siRNA targeted to MRP1 mRNA as a suppressor of pump drug resistance and siRNA targeted to BCL2 mRNA as a suppressor of nonpump cellular resistance) and an analog of luteinizing hormone-releasing hormone as a targeting moiety to lungs. The inhalation of the NLCs by an orthotopic mice model of human lung cancer resulted in efficient suppression of tumor growth and prevention of adverse side effects on healthy organs.

3.3. Lipid Drug Conjugates (LDCs). LDCs are the most accepted lipid-based nanoparticle systems for the delivery of hydrophilic drugs, as they improve the drug loading capacity of SLNs and NLCs. In LDC nanoparticles, hydrophilic drugs are first conjugated with lipid components by covalent linking between an amino group or a hydroxyl group of the drug and carboxyl groups of the lipid core to obtain a lipophilic complex [93]. The water insoluble LDC is converted to nanoparticles by means of traditional methods used to prepare SLNs or NLCs $[94,95]$.

LDCs have shown hopeful results as delivery system for hydrophilic antitrypanosomal drugs [96, 97], for oral application of methotrexate [94], and, more recently, for chemotherapy agents $[1,95]$, such as decitabine, a drug that shows low oral bioavailability [98]. Neupane et al. [99] developed LDC nanoparticles of decitabine to increase its permeability and protect against chemical degradation. LDCs were obtained by salt formation of DCB with stearic acid to be formulated as LDC nanoparticles by cold high-pressure homogenization after addition of surfactants Tween 80, Poloxamer 188, and Labrasol. Ex vivo gut permeation studies proved that the drug in LDC nanoparticles showed nearly fourfold increase in the apparent permeability coefficients with respect to the plain decitabine.

3.4. Cationic Emulsions. Emulsions are dispersions of one immiscible liquid in another stabilized by a third component, 
the emulsifying agent [100]; therefore, they present in their composition three components: oil, water, and surfactants. When cationic surfactants are used, these dispersed systems make them suitable for gene delivery. The presence of cationic surfactants causes the formation of positively charged droplets that promote strong electrostatic interactions between emulsion and the anionic nucleic acid phosphate groups. Cationic emulsions composed of cationic lipids and core oil have been shown to be useful for gene delivery $[101,102]$. The colipid DOPE is largely used to improve the ability of cationic emulsions and liposomes to transfect cells due to its fusogenic properties. This can be partially explained by the fact that the amine group of DOPE interacts with DNA phosphate groups, thus weakening the binding affinity between cationic lipids and DNA [100].

In spite of the advantages of nanoemulsions for delivery of nucleic acids, only few attempts have been made to use this new delivery system for RNAi. For instance, Kaneda et al. [103] showed the potential application of cationic nanoemulsion prepared with DOTAP, DOPE, and cholesterol for siRNA delivery. Transfection complexes, with a mean particle diameter of approximately $300 \mathrm{~nm}$, were able to suppress endothelial cell expression of upregulated vascular adhesion molecules. To the knowledge of the authors, no studies about cationic emulsions with RNAi molecules to treat viral infections have been published.

3.5. Liposomes. Liposomes are colloidal lipid- and surfactantbased delivery systems, composed of a phospholipid bilayer surrounding an aqueous compartment. They may present as spherical vesicles and can range in size from $20 \mathrm{~nm}$ to a few microns. Cationic lipid-based liposomes are able to complex with negatively charged nucleic acid via electrostatic interactions, resulting in complexes that offer biocompatibility, low toxicity, and the possibility of large-scale production required for in vivo clinical applications [104]. The lipid to RNA ratio and overall lipid concentration used in forming these complexes are very important for efficient gene delivery and vary with applications. Liposomes can fuse with the plasma membrane for uptake; once inside the cell, the liposomes are processed via the endocytic pathway and the genetic material is then released from the endosome/carrier into the cytoplasm. Compared to polymeric nanoparticles, liposomes have long been perceived as better drug delivery vehicles because of their superior biocompatibility, as liposomes are basically analogues of biological membranes, which can be prepared from both natural and synthetic phospholipids [104].

Neutral lipids are highly nontoxic and do not activate an immune response [105]. 1,2-Oleoyl-sn-glycero-3phosphocholine (DOPC) and DOPE are among the most widely used neutral lipids. Simply mixing siRNA with DOPC results in high encapsulation efficiency [106]. However, neutral liposomes yield relatively low transfection efficiency. Cationic lipids, such as 1,2-dioleoyl-3-trimethylammoniumpropane (DOTAP), can complex electrostatically with siRNAs and be used to create a more effective liposome as the positively charged lipids provide enhanced cell entry and increased protection against serum enzymes [107].

Although liposomes are one of the most commonly used transfection reagents in vitro, safe and efficacious delivery in vivo is more difficult to achieve due to toxicity, nonspecific uptake, and unwanted immune response. Much of the nonspecific response and toxicity is directly linked to the positive charge on the surface of the particles necessary for the binding of oligonucleotides. In order to improve their behavior, in recent years, significant effort has been dedicated to modifying the composition and chemical structure of liposomes. For instance, different additives, such as hydrophobic cholesterol, nonionic surfactants, or PEG, can be used to enhance in vivo stability after exposure to blood components [108]. It has been reported that the stability-enhanced liposomes have much better transfection efficiencies, especially under in vivo conditions [109]. To increase specificity, PEGylated immunoliposomes conjugated with targeting ligands have been developed [110].

Liposomes have been widely studied as RNAi carriers as potential treatment of viral infections such as $\mathrm{HCV}, \mathrm{HBV}$, and $\mathrm{VIH}$, among others $[33,34,48,49,111]$.

\section{Lipid Nanoparticles as RNAi Carriers against Viral Infections}

As mentioned above, an effective delivery system will have to be developed for exploiting the gene silencing by RNA interference strategy for antiviral therapy. The applicability of LNP for the treatment of viral infections is emerging in the last years. On the one hand, the use of LNP as nonviral nanocarriers of gene material is the most studied approach. In this sense, some researchers suggest the simultaneous administration of different siRNAs or shRNAs to avoid the important payload of viral mutation escape [112]. On the other hand, the prophylaxis for viral infections using RNAi has been considered a promising strategy.

The RNAi process requires a high specificity of gene sequences and the choice of the target is the most crucial step for a successful viral inhibition. It is very important to design siRNA against very highly conserved sequences of the viral genome in order to optimize efficacy in inhibiting a majority of virus straints. In addition to its utility as a stand-alone strategy, RNAi may have expanded applications as an adjuvant in multipronged treatment settings. Another RNAi adjuvant strategy is the use of dsRNA oligonucleotides as immunostimulatory agonists alongside vaccines, as in the case of a RIG1 agonist to enhance the activity of a DNA vaccine against influenza [113].

4.1. Hepatitis $C$ Virus (HCV). According to the World Health Organization (WHO), every year, 3-4 million people are infected with the HCV, and about 150 million people are chronically infected, which can lead to liver cirrhosis and/or hepatocellular carcinoma (liver cancer). In consequence, more than 350000 people die from hepatitis C-related liver diseases every year [114]. 
Combination of generic antiviral agents, IFN- $\alpha$ and ribavirin, is the mainstay of current hepatitis $\mathrm{C}$ treatment. Unfortunately, IFN- $\alpha$ is not available in some countries, people do not always tolerate well this drug, and many people do not finish their treatment. In addition, some virus genotypes do not respond well to IFN- $\alpha$ [115]. Recently new antiviral drugs, telaprevir or boceprevir, have been added to set up the so-called triple therapy; the experience in patients with chronic hepatitis $C$ genotype 1 shows that this new combination is superior to dual therapy in terms of sustained virologic response [116]. However, genotype independent alternatives should be more effective in the treatment and prevention of this liver infection. In this regard, the RNAi technology is an attractive strategy.

$\mathrm{HCV}$ is a RNA virus belonging to Flaviviridae family. The single-stranded RNA genome of this virus acts also as mRNA, which makes it an attractive target for RNAibased therapy. Several works show potent HCV replication inhibition by using chemically synthesized siRNAs targeted against sequences in the protein-coding regions of core, E2, NS3, NS5B, or NS4 [117-119]. However, these viral coding sequences suffer variations among different HCV genotypes. Therefore, highly conserved regions, such as $5^{\prime}$ untranslated regions ( $5^{\prime} \mathrm{UTR}$ ), seem to be better targets for developing a rational antiviral strategy [120]. The replication of different HCV genotypes has been inhibited by targeting $5^{\prime}$ UTR with synthetic siRNA or shRNA expression [121-123]. The main limitation of all these new strategies lies in the emergence of resistant virus variants due to the high specificity of RNAi and the prolonged treatment. In order to prevent escape mutants, some approaches have been proposed. The internal ribosome entry site (IRES) in the $5^{\prime}$ UTR is required for the synthesis of viral proteins and, therefore, for viral replication. Mutations in these structures might lead to loss of function [9], making IRES an excellent target for anti-HCV drugs, which might prevent viral escape; it has also been targeted by the RNAi technology [124]. Another possibility to reduce resistant variants is the combination of two or more RNAi molecules with different specificities [125] targeted to separated regions of the HCV genome. Targeting multiple sites of the HCV genome and host genes necessary for virus replication has also been documented as a valid approach to prevent the development of resistance $[126,127]$.

Among the RNAi delivery systems against HCV, cationic lipid-based nanoparticles play an interesting role; these lipidbased vectors are well characterized as nanocarriers for systemic delivery of RNAi molecules to the liver, due to their safety profile and simplicity of production. Table 2 summarizes the strategies employed by different authors to improve the efficacy of lipid nanosystems in RNAi-mediated therapies against $\mathrm{HCV}$.

Watanabe et al. [33] designed lactosylated cationic liposomes to deliver siRNA targeting the $5^{\prime}$-UTR and $3^{\prime}$-UTR of the HCV genome into mouse liver hepatocytes; the galactose terminus of lactose is a ligand of the asialoglycoprotein receptor, which is specifically expressed in the surface of hepatocytes. Intravenous administration of the mentioned vectors into $\mathrm{HCV}$-transgenic mice resulted in a decrease of HCV core protein.
Another possibility is the functionalization of LNP with apolipoproteins. Kim et al. [34] developed liver-specific siRNA delivery vectors composed of cationic liposomes and apolipoprotein A-1 (apo A-1) derived from human plasma. This protein, component of high density lipoprotein (HDL), has been proposed as a targeting ligand to hepatocytes [48]. After intravenous administration of the lipid-based systems containing $\mathrm{HCV}$-core specific siRNA into an $\mathrm{HCV}$ mouse model, viral expression was inhibited by $65-75 \%$ in the liver on day 2. In the same work, the chemical modification of the HCV-core specific siRNA to increase its serum stability resulted in gene silencing efficacy up to $95 \%$ for at least 6 days. In order to avoid safety problems related to the risk of pathogen contamination associated with the use of plasma-derived protein, in a posterior work [35] apo A-1 was substituted by a recombinant human apo A-1 (rhapo A-1). This new apolipoprotein of low endotoxin grade was expressed and purified from an Escherichia coli expression system. The use of rhapo A-1 to deliver siRNA to the liver resulted as effective and selective as plasma-derived apo A-1, without affecting the normal liver function.

The choice of an adequate RNAi molecule is also crucial. HCV replication has also been inhibited both in vitro and in vivo by delivery of different siRNAs with lipid nanosomes composed of the cationic lipid DOTAP, the helper lipid cholesterol, and the peptide protamine. Nanosomes are nanosize unilamellar vesicles obtained by high-pressure homogenization of lipid dispersions [36, 128]. In a first work, nanovectors were optimized in terms of lipid-to-siRNA ratio and favorable particle size depending on sonication time. Cell viability was maintained about $90 \%$ and $\mathrm{HCV}$ inhibition reached approximately $85 \%$ [128]. Later on, the cationic lipid nanosomes were used to complex different siRNA targeted to the $5^{\prime} \mathrm{UTR}$ of the HCV genome. Chandra et al. compared repeated treatments with two-siRNA versus a single siRNA treatment. A reduction in the development of resistant mutants to the siRNA therapy was observed when the combinatorial strategy was used, and after systemic injection in a liver tumor-xenotransplant mouse model of HCV, significant inhibition of virus replication was obtained [36]. More recently, short synthetic shRNAs (sshRNAs) that target a sequence within IRES have been formulated into LNP by the process of step-wise ethanol dilution and spontaneous vesicle formation. sshRNA was dissolved in an aqueous solution containing 30\% ethanol and added to preequilibrated LNP at $35^{\circ} \mathrm{C}$. After reaching the final sshRNA to lipid ratio, the mixture was incubated for further $30 \mathrm{~min}$ at $35^{\circ} \mathrm{C}$ to allow vesicle reorganization and encapsulation of the RNA. Finally, LNP were dialyzed against PBS and filter sterilized through a $0.2 \mu \mathrm{m}$ filter. The intravenous injection of this vector resulted in enough uptake by the hepatocytes to substantially suppress gene expression in a rapid and durable manner [37].

4.2. Hepatitis B Virus (HBV). WHO estimates that about 600,000 people die every year due to the consequences of $\mathrm{HBV}$ infection (mainly cirrhosis of the liver and liver cancer). A vaccine against hepatitis B has been available since 1982 . Hepatitis B vaccine is $95 \%$ effective in preventing infection 
TABLE 2: Studies carried out with lipid-based nanosystems as RNAi delivery vectors against hepatitis C (HCV).

\begin{tabular}{|c|c|c|c|c|c|}
\hline Lipid nanosystem & RNAi & $\begin{array}{l}\text { Targeting } \\
\text { molecule }\end{array}$ & Culture cells & In vivo model & Reference \\
\hline $\begin{array}{l}\text { Cationic } \\
\text { liposomes }\end{array}$ & $\begin{array}{l}\text { siRNAs against the } \\
5^{\prime} \text {-UTR and } 3^{\prime} \text {-UTR of } \\
\text { the HCV genome }\end{array}$ & Lactosylated-PE & $\begin{array}{l}\text { FLR3-1 and } \\
\text { R6FLR-N cells }\end{array}$ & $\mathrm{CN} 2-29$ transgenic mice & {$[33]$} \\
\hline $\begin{array}{l}\text { Cationic } \\
\text { liposomes }\end{array}$ & $\begin{array}{l}\text { HCV-core specific } \\
\text { siRNA (siHCc) }\end{array}$ & Apo A-I & Huh7 & $\begin{array}{l}\text { HCV mouse model constructed } \\
\text { by hydrodynamic injection of } \\
\text { DNA plasmid expressing viral } \\
\text { proteins }\end{array}$ & {$[34]$} \\
\hline $\begin{array}{l}\text { Cationic } \\
\text { liposomes }\end{array}$ & $\begin{array}{l}\text { HCV-core specific } \\
\text { siRNA (siHCc) }\end{array}$ & $\begin{array}{l}\text { Recombinant } \\
\text { human apo A-I }\end{array}$ & - & $\begin{array}{l}\text { HCV mouse model constructed } \\
\text { by hydrodynamic injection of } \\
\text { DNA plasmid expressing viral } \\
\text { proteins }\end{array}$ & {$[35]$} \\
\hline $\begin{array}{l}\text { Cationic } \\
\text { nanosomes }\end{array}$ & $\begin{array}{l}\text { siRNAs against hte } \\
\text { stem-loop domains } \\
\text { II-IV of HCV 5/UTR }\end{array}$ & - & $\begin{array}{l}\text { Huh- } 7.5 \text { and } \\
\text { R4-GFP cells }\end{array}$ & $\begin{array}{l}\text { HCC tumor-xenograft mice } \\
\text { model for HCV }\end{array}$ & {$[36]$} \\
\hline Cationic LNP & $\begin{array}{l}\text { sshRNA targeting the } \\
\text { HCV IRES }\end{array}$ & - & - & $\begin{array}{l}\text { Reporter mice that express in the } \\
\text { liver firefly luciferase under the } \\
\text { control of the HCV IRES }\end{array}$ & {$[37]$} \\
\hline
\end{tabular}

Lactosylated-PE: lactosylated-phosphatidylethanolamine; FLR3-1 cells: HuH-7 cells bearing an HCV subgenomic replicon (genotype 1b); R6FLR-N cells: HuH7 cells bearing an HCV subgenomic replicon (genotype 1b); CN2-29 transgenic mice: mice that carry an HCV transgene; Apo A-I: apolipoprotein A-I; Huh7 cells: human hepatoma cell line; Huh7.5 cells: Huh7 cells that contain a mutation in RIG-I believed to be responsible for the improved replication of HCV; R4GFP cells: IFN- $\alpha$-resistant HCV-GFP chimer replicon cell line; HCC: hepatocellular carcinoma; LNP: lipid nanoparticles; IRES: internal ribosome entry site.

but offers scarce therapeutic benefit to chronic carriers [129]. Some people with chronic hepatitis B are treated with drugs, including IFN, nucleotide/nucleoside analogues, and immunomodulators, but there is no specific treatment for acute hepatitis B [130]. Moreover, current therapies have limited efficacy, are expensive, produce side effects, and are associated with viral resistance [131]. The emergence of resistance has been reduced by new antivirals (entecavir or tenofovir), but patients usually need to take these drugs for life, because interruption of treatment quickly reactivates viral replication [132]. Therefore, there is need for finding effective therapies against HBV, with the use of RNAi being an attractive possibility. RNAi has also been studied as a possible vaccine against HBV [133], but its main application is the treatment of chronic HBV infection.

HBV viron contains a partly double-stranded relaxed circular DNA (rcDNA) that is encapsidated by core proteins and enveloped with $\mathrm{S}$ proteins and membrane lipids from the host to form viral particles [134]. When a hepatocyte is infected endogenous repair enzymes convert rcDNA in a fully double-stranded, circular, and supercoiled DNA (cccDNA), which serves as template for transcription of HBV RNA. Expression of viral proteins and viral replication may be potentially knocked down by RNAi-based therapeutics.

RNAi activators used against HBV include expressed or engineered synthetic RNAi intermediates; each class of silencing molecules has advantages and disadvantages. Expressed anti-HBV sequences, as plasmids that produce specific siRNAs [135] or as shRNA [136-140], have demonstrated efficacy in vitro and in vivo and they achieve more sustained silencing effect, whereas synthetic siRNAs require repeated administration to provide a long-term suppression of $\mathrm{HBV}$ replication [141-143]. However, expressed RNAi activators are complex in terms of delivery and dose control, which have led to the development of chemically modified synthetic siRNAs with the aim of improving silencing efficacy, specificity for a particular target mRNA, avoidance of innate immunostimulation, stability, and delivery to target tissue $[51,144]$.

The delivery of these RNAi molecules against HBV has been addressed by several research groups by means of cationic lipid-based systems, recapitulated in Table 3 . In an early study, Morrissey et al. [47] entrapped a couple of chemically modified synthetic anti-HBV siRNAs in stable nucleicacid-lipid particles (SNALPs). SNALPs consist of a lipid bilayer composed of cationic and fusogenic lipids, which are coated with a PEG-lipid. Inner lipids enable cellular uptake and endosomal release of the molecules payload, whereas the coating stabilizes the particles during formulation and shields the particles in vivo to avoid rapid systemic clearance. Following administration, the PEG-lipid dissociates from the nanoparticles and the SNALPs become a transfectioncompetent entity [145]. After intravenous administration of SNALPs-siRNA vectors to mice carrying the replicating virus, encapsulated siRNA presented a longer half-life in plasma and liver than nonencapsulated. Sustained specific reduction in $\mathrm{HBV}$ titers, for up to 7 days, and reduced toxic and immunostimulatory side effects were achieved [47]. Like in the case of $\mathrm{HCV}$, in order to improve liver-targeting, apo A-1 has been combined with the cationic lipid DOTAP and the helper lipid cholesterol to form lipoplexes with siRNAs against HBV [48]; apo A-1 was incorporated into the formulation by reassembling the liposomes with a solution of the protein at $4^{\circ} \mathrm{C}$ overnight. Intravenous injection of these lipoplexes into a HBV mouse model significantly reduced viral protein expression during at least 8 days in only a single 
TABLE 3: Studies carried out with lipid-based nanosystems as RNAi delivery vectors against hepatitis B (HBV).

\begin{tabular}{|c|c|c|c|c|c|}
\hline Lipid nanosystem & RNAi & $\begin{array}{l}\text { Targeting } \\
\text { molecule }\end{array}$ & Culture cells & In vivo model & Reference \\
\hline SNALP & $\begin{array}{l}\text { HBV siRNAs chemically } \\
\text { stabilized for nuclease } \\
\text { resistance }\end{array}$ & - & $\begin{array}{l}\text { HBV-replicating } \\
\text { HepG2 }\end{array}$ & $\begin{array}{l}\text { HBV mouse model constructed } \\
\text { by hydrodynamic injection of } \\
\text { HBV vector DNA }\end{array}$ & {$[47]$} \\
\hline Cationic liposomes & $\begin{array}{l}\text { HBV-X specific siRNA } \\
(\text { siHBV) }\end{array}$ & Apo A-I & HepG2 and Huh7 & $\begin{array}{l}\text { Acute HBV-infected mouse } \\
\text { model by hydrodynamic } \\
\text { injection of a plasmid }\end{array}$ & {$[48]$} \\
\hline $\begin{array}{l}\text { PEGylated cationic } \\
\text { liposomes }\end{array}$ & HBV specific siRNA & - & $\begin{array}{l}\text { Huh7 cells } \\
\text { previously } \\
\text { transfected with } \\
\text { HBV replication } \\
\text { target plasmid }\end{array}$ & HBV transgenic mice & {$[49]$} \\
\hline DODAG 8 lipid & HBV specific siRNA & - & - & HBV transgenic mice & {$[50]$} \\
\hline Cationic liposomes & $\begin{array}{l}\text { Altriol modified HBV-X } \\
\text { siRNA }\end{array}$ & Galactose & $\begin{array}{l}\text { Huh7 cells } \\
\text { previously } \\
\text { transfected with } \\
\text { HBV target DNA } \\
\text { plasmid }\end{array}$ & HBV transgenic mice & {$[51]$} \\
\hline
\end{tabular}

SNALP: stable nucleic acid lipid particle; HepG2: liver hepatocellular carcinoma cells; HuH7: human hepatoma cell line; DODAG: $N^{\prime}, N^{\prime}$-dioctadecyl- $N$-4,8diaza-10-aminodecanoylglycine amide.

treatment. In two subsequent studies, lipid-based systems demonstrated more effective or comparable inhibition of viral proliferation than lamivudine, a licensed HBV drug $[49,50]$. In one case [49], lipoplexes were prepared by adding an aqueous solution of siRNA targeting conserved regions of the HBV genome to a dispersion of lipid vesicles with constant vortex mixing. Thereafter, a PEG-lipid was added to the lipoplexes and the mixture was incubated for $16 \mathrm{~h}$. These vectors were also lyophilized in presence of trehalose for long-term storage. In the second case [50], the siRNA targeting conserved regions of the $\mathrm{HBV}$ genome was combined with the cationic lipid $\mathrm{N}^{\prime}, \mathrm{N}^{\prime}$-dioctadecyl-N-4,8-diaza10 -aminodecanoylglycine amide (DODAG) under conditions of rapid vortex mixing to produce siRNA-DODAG nanoparticles. More recently, a liver-targeting cholesterol galactoside was incorporated into lipoplexes to obtain an altriol-modified siRNA delivery system [51]. The galactoseconjugated cholesterol was synthesized by a cooper-mediated "click" reaction between the 2-propynylcarbamate derivative of cholesterol and $O$-tetraacetate galactose azide. This lipid was mixed with a nucleic acid binding cholesterol derivative and the helper lipid to obtain liposomes capable of binding the siRNA. The improved hepatotropism and attenuated immunostimulatory properties of the vectors demonstrated that galactose functionalization has also potential for delivery of RNAs to hepatocytes in the treatment of hepatic viral infections and other liver diseases.

4.3. Human Immunodeficiency Virus (HIV). HIV continues to be a major global public health issue, having claimed more than 36 million lives so far. In 2012, approximately 35.3 million people lived infected by HIV [146]. Although effective treatment with antiretroviral drugs can control the virus, there is no cure for HIV infection; therefore, novel and more promising strategies must be developed.

HIV belongs to retroviruses, which are viruses that contain RNA as genetic material. Throughout its life cycle, the RNA of HIV is not protected during viral uncoating and reverse transcription. At this point, therapeutic RNAi molecules may interact with viral RNA and blockage or reduce HIV infection. Synthetic and expressed RNAi have been evaluated preclinically to target HIV-encoded RNA such as rev, nef, or integrase [147-149] or host factors, mainly the chemokine receptor 5 (CCR5) [111, 150, 151], a promising target because it is apparently not important for human physiology [152]. Some of these targets have also been evaluated in the clinical practice, by using lentiviral or ex vivo strategies, but the drawbacks related to immunogenicity of the vectors and/or inconveniences for patients call for new delivery systems [153-156]. In addition, as with other viruses, when only one RNAi is targeted escape mutants can be generated [157]; targeting multiple viral targets, combinations of host and viral proteins, even combining host, viral proteins, and clinically approved antiretroviral drugs have demonstrated improved efficacy against HIV [152, 158-160].

In the field of vaccines against HIV, RNAi may also play an important role. On the one hand, RNAi technology has been proposed as a strategy to block genes related to the suppression of immune response mediated by DNA vaccines, which are limited in nonhuman primates and humans, probably due to the relative brief duration of vaccine antigen expression in vivo. After intramuscular (i.m.) administration of plasmid DNA in mice, an adaptive immune response that mediates the apoptotic destruction of vaccine antigenexpressing myocytes was detected [161]. The use of a shRNA targeted to caspase-12, a cell death mediator activated after plasmid DNA vaccination, resulted in increased HIV-gp120 
Env antigen expression and higher CD8 T cell and antibody responses [162]. On the other hand, siRNA can be used in a prophylactic manner. For instance, siRNAs designed to knock down CCR5 and/or viral genes in CD4+ T cells, macrophages, and dendritic cells have shown protection capacity against HIV vaginal transmission when applied intravaginally to humanized mice [163]. In this regard, LNP may be the delivery system of choice, as they have demonstrated adjuvant properties for HIV vaccine. Anionic SLNs prepared with an emulsifying wax and coated with the HIVTat (transactivator of transcription) protein and administered subcutaneously twice to mice at an interval of 2 weeks elicited IgG and IgM responses similar to the commonly used adjuvant Alum and a higher release of IFN- $\gamma$ in splenocytes [164]. In addition, anti-Tat IgG titers obtained with Alum carrying Tat were lower than those obtained with a reduced dose of the peptide adjuvanted with the SLN [165]. Other administration routes have also been explored. Intradermal and intranasal administration in mice of carnauba wax based SLN coated with HIV gp140 antigen and toll-like receptor-9 (TLR-9) yielded higher systemic and mucosal immunity than the antigen alone [166]. In another work, liposomes bearing anti-CCR5 siRNA were functionalized with the monoclonal antibody (mAbd) against lymphocyte function-associated antigen-1 (LFA-1) integrin. After intravenous administration into humanized mice, leukocyte-specific gene silencing was obtained during 10 days, and when challenged with HIV plasma viral load and loss of CD4 T cells were reduced [111].

4.4. Other Viral Infections. Although HCV, HBV, and HIV are the most studied, RNAi with lipid formulations has also been applied to the potential treatment of other viral infections such as herpes simplex virus, Ebola virus, human papillomavirus (HPV), or rabies virus, among others.

Herpes simplex virus-2 (HSV-2) infection causes significant morbidity and is an important cofactor for the transmission of HIV infection. In a study carried out by Palliser et al. [167], seven siRNAs targeting three essential HSV-2 genes (UL5 (a component of the helicase-primase complex), UL27 (envelope glycoprotein B), and UL29 (a DNA-binding protein)) were prepared and assayed for viral protection. siRNAs lipoplexes were efficiently taken up by epithelial and lamina propria cells and silenced gene expression in the mouse vagina and ectocervix for at least nine days. Intravaginal application of siRNAs targeting the HSV2 UL27 and UL29 genes was well tolerated, did not induce IFN-responsive genes or cause inflammation, and protected mice when administered before and/or after lethal HSV-2 challenge. In a later study [168], one of the viral siRNAs was combined with a siRNA targeting the HSV-2 receptor nectin-1. Cholesterol-conjugated- (chol-) siRNAs silenced gene expression in the vagina without causing inflammation or inducing IFNs. The viral siRNA prevented transmission within a day of challenge, whereas the siRNA targeting the HSV-2 receptor nectin-1 protected for a week, but protection is delayed for a few days until the receptor is downmodulated. Combining siRNAs targeting a viral and host gene protected mice from HSV-2 for a week, irrespective of the time of challenge.

Ebola virus (EBOV) infection causes a frequently fatal hemorrhagic fever that is refractory to treatment with currently available antiviral therapeutics. Geisbert et al. [169] prepared four siRNAs targeting the polymerase gene of the Zaire species of EBOV (ZEBOV) and complexed them with polyethylenimine or formulated them in SNALPs. Guinea pigs were treated with these siRNAs either before or after lethal ZEBOV challenge. Treatment of guinea pigs with a pool of the L gene-specific siRNAs delivered by polyethylenimine polyplexes reduced plasma viremia levels and partially protected the animals from death when administered shortly before the ZEBOV challenge. Evaluation of the same pool of siRNAs delivered using SNALPs proved that this system was more efficacious, as it completely protected guinea pigs against viremia and death when administered shortly after the ZEBOV challenge. Additional experiments showed that 1 of the 4 siRNAs alone could completely protect guinea pigs from a lethal ZEBOV challenge. In a later study [170], the same research group assessed the efficacy of modified nonimmunostimulatory siRNAs in a uniformly lethal nonhuman primate model of ZEBOV haemorrhagic fever. Two (66\%) of three rhesus monkeys given four postexposure treatments of the pooled anti-ZEBOV siRNAs were protected from lethal ZEBOV infection, whereas all macaques given seven postexposure treatments were protected. The treatment was well tolerated with minor changes in liver enzymes that might have been related to viral infection. From results obtained in these studies, in January 2014, a Phase I clinical trial commenced, as it will be mentioned in Section 5 of this review.

The human papillomavirus (HPV) is the etiologic agent of cervical cancer. The E7 gene is a promising target for RNAi application in the management of HPV infection [171]. It plays an important role in cell-cycle regulation. Moreover, E7 inhibits the therapeutic effect of antiviral agents (such as IFN$\alpha$ ) and suppresses local immunity through functional inhibition of antigen-presenting cells and cytotoxic T lymphocytes. E7 gene silencing in high risk HPV types such as HPV16 and HPV-18 by siRNAs suppressed cell growth in vitro and in vivo. siRNA duplexes or shRNA-expressing plasmids targeting the E7 genes of HPV-6b or HPV-11 were inoculated into cultured E7-expressing cells via cationic liposomes or into E7 gene-expressing mouse tumor models intratumorally or intravenously [170]. Both siRNAs and shRNA-expressing plasmids reduced in vitro the mRNA levels of HPV-6b or HPV-11 E7 to 20-40\%. E7 mRNA expression in tumor models was reduced to $45-50 \%$ after three intratumoral injections. Intratumoral injections of RNAi effectors induced greater inhibition than did intravenous injections.

Rabies virus (RABV) infection continues to be a global threat to human and animal health, yet no curative therapy has been developed. siRNAs that target the conserved region of the RABV challenge virus standard (CVS)-11 strain nucleoprotein gene represent a promising approach for treating RABV infections [172]. Using a plasmid-based transient expression model, these siRNAs were capable of significantly inhibiting viral replication in vitro and in vivo. 
They effectively suppressed RABV expression in infected baby hamster kidney-21 (BHK-21) cells, as evidenced by direct immunofluorescence assay, viral titer measurements, real-time PCR, and Western blotting. In addition, liposomemediated siRNA expression plasmid delivery to RABVinfected mice significantly increased survival, compared to a nonliposome-mediated delivery method.

siRNA immunoliposomes have also been shown as a therapeutic agent against $\mathrm{H} 5 \mathrm{~N} 1$ influenza virus infection. In a recent study [173], siRNA specific for influenza virus nucleoprotein (NP) mRNA was employed as the key antiviral agent to inhibit viral replication. A humanized single-chain Fv antibody (huscFv) against the hemagglutinin (HA) of H5N1 highly pathogenic avian influenza virus (HPAI) was used as the targeting molecule to $\mathrm{HA}$ of $\mathrm{H} 5 \mathrm{~N} 1$ virus, which is abundantly expressed on the surface of infected cells (the HA target cells). The immunoliposomes were shown to specifically bind HA-expressing Sf9 cells and demonstrated enhanced siRNA transfection efficiency. Furthermore, the siRNA silencing effect was more pronounced when the immunoliposomes were administered 6 to $12 \mathrm{~h}$ after H5N1 infection in MDCK cells compared with the nontargeted liposomes.

In a recent study [174], liposomes were used to deliver a self-amplifying RNA vaccine for respiratory syncytial virus (RSV). The vaccine potently induced neutralizing antibodies in cotton rats, as well as antigen-specific IFN- $\gamma$-producing $\mathrm{CD} 4+$ and $\mathrm{CD} 8+\mathrm{T}$ cells in mice. These responses were comparable to or exceeding those elicited by RNA delivered by viral particles or electroporation of pDNA and provided protection against subsequent RSV infection.

\section{Clinical Development of LNP-RNAi for Viral Infections}

The exhaustive work undertaken in preclinical studies (both in vitro in culture cells and in vivo in animals) has shown that RNAi therapeutic against viral infections is highly effective at reducing virus replication and also useful as a tool to rapidly identify novel antiviral drug targets via large-scale screens for a number of viral infections [175]. Several novel viral targets have been identified and are the subject of intense research and development, but definitive evidence is lacking from well-controlled studies that demonstrate the effectiveness in these infection diseases [176]. Therefore, the next logical step must consist of human clinical trials that depict the realistic possibilities of this kind of therapy in viral infections.

The number of RNAi-based clinical trials for viral infections has grown over the past several years and has included studies against respiratory syncytial virus (RSV), HCV, HBV, HIV, and Ebola virus [177], some of them using lipid-based systems as vectors. Table 4 collects the clinical trials evolving the application of RNAi molecules to the treatment of viral infections.

Alnylam Pharmaceuticals Inc. has carried out clinical trials with a naked siRNA against RSV nucleocapsid (ALNRSV01). A Phase IIb study in adult lung transplant patients showed that this candidate is a promising alternative for RSVinduced bronchiolitis obliterans syndrome (BOS) that causes significant morbidity and mortality in this group of patients; moreover, the treatment with the siRNA was safe and well tolerated, and it was associated with more than $50 \%$ reduction in the incidence of new or progressive BOS at days 90 and 180 [52].

The international clinical-stage biopharmaceutical company Santaris Pharma A/S has developed an anti-miRNA drug candidate currently in clinical testing (Phase II) for treatment of HCV infections (Miravirsen, SPC3649). This drug acts against MiR-122, a liver-specific miRNA that the HCV requires for replication [53]. Data from the Phase IIa trial showed that Miravirsen was well tolerated by patients with chronic HCV genotype 1, given as weekly subcutaneous injections, over 4 weeks. Antiviral activity was continued and prolonged well beyond the end of active therapy. These data provide clinical evidence about the potential of Miravirsen as once weekly monotherapy for chronic HCV [54]. Although in a less advanced state, Benitec Biopharma Ltd., with its subsidiary Tacere Therapeutics, has designed a shRNAibased multicassette vector called TT-034, which targets 3 well-conserved regions of HCV simultaneously, thus preventing generation of drug-resistant mutants. In addition, the targeted regions are conserved across all genotypes. Recently Benitec Biopharma Ltd. has announced that the first patient enrolled in the "first in man" Phase I/II clinical trial for TT034 has received the first dose [55].

The biopharmaceutical company Arrowhead Research Corporation has recently presented data on the Phase I clinical study of ARC-520, the company's clinical candidate for the treatment of chronic HBV infection. ARC-520 is a siRNA-based therapeutic composed of a hepatocyte-targeted peptide (NAG-MLP) that promotes the endosomal escape of the liver tropic HBV cholesterol-siRNA. Although additional blinding results are still missing, initial results in 36 healthy volunteers receiving different doses indicate that ARC-520 is well tolerated at doses expected to be efficacious in patients with chronic HBV [178], and a Phase IIa clinical trial has recently begun [56]. The study is planned to enroll up to 16 chronic HBV patients in two-dose cohorts with patients receiving either ARC-520 or placebo in combination with entecavir. The study is designed to evaluate the depth and duration of hepatitis B surface antigen (HBsAg) decline, among other measures, in response to a single dose of ARC520.

In the case of HIV an ex vivo silencing approach has been developed by the company Calimmune, by using shRNA licensed by Benitec Biopharma. $\mathrm{T}$ cells are extracted from HIV patients, the gene that codes for the CCR5 receptor protein is silenced ex vivo and re-injecting the modified cells, resistance to HIV is conferred to the patients. In its Phase 1/ll clinical trial of the treatment, the enrolment of the first cohort of patients, which corresponds to the group that will receive modified CD4+ T cells and CD34+ stem cells, is about to be completed [57].

Finally, siRNA delivery against Ebola virus is also being under subject of a Phase I clinical trial recently initiated. Tekmira Pharmaceuticals has developed a therapeutic product 
TABLE 4: Clinical trials evolving the application of RNAi in the treatment of viral infections.

\begin{tabular}{|c|c|c|c|c|c|}
\hline Clinical candidate & Targeting virus & $\begin{array}{l}\text { RNAi } \\
\text { molecule }\end{array}$ & Clinical phase & Company & Reference \\
\hline ALN-RSV01 & RSV & siRNA & $\mathrm{IIb}$ & Alnylam Pharmaceuticals Inc. & {$[52]$} \\
\hline Miravirsen, SPC 3649 & $\mathrm{HCV}$ & antimiRNA & IIa & Santaris Pharma A/S & {$[53,54]$} \\
\hline TT-034 & $\mathrm{HCV}$ & shRNA & $\mathrm{I} / \mathrm{IIa}$ & Benitec Biopharma Ltd. & {$[55]$} \\
\hline ARC-520 & $\mathrm{HBV}$ & siRNA & II & $\begin{array}{l}\text { Arrowhead Research } \\
\text { Corporation }\end{array}$ & {$[56]$} \\
\hline $\begin{array}{l}\text { CCR5 negative cells } \\
\text { (generated ex vivo) }\end{array}$ & HIV & shRNA & $\mathrm{I} / \mathrm{II}$ & $\begin{array}{l}\text { Calimmune and Benitec } \\
\text { Biopharma Ltd. }\end{array}$ & {$[57]$} \\
\hline TKM-Ebola & Ebola virus & siRNAs & $\mathrm{I}$ & Tekmira Pharmaceuticals & {$[58]$} \\
\hline
\end{tabular}

CCR5: chemokine receptor 5; RSV: respiratory syncytial virus; HCV: hepatitis C virus; HBV: hepatitis B virus; HIV: human immunodeficiency virus; siRNA: short interfering RNA; miRNA: microRNA; shRNA: short hairpin RNA.

composed of a combination of modified siRNAs targeting the Zaire Ebola polymerase, viral protein (VP) 24, and VP35 formulated in LNP (TKM-Ebola). The Ebola Phase I clinical trial is a randomized, single-blind, placebo-controlled study involving single ascending doses and multiple ascending doses of the lipid nanoparticle based formulation (TKMEbola). The study will assess the safety, tolerability, and pharmacokinetics of administering TKM-Ebola to healthy adult subjects [58].

\section{Conclusions and Future Perspectives}

As summarized in this review, RNAi is a promising therapeutic strategy due to its ability to silence any gene with a known sequence. However, the use of RNAi in the clinic is limited by the complexity of effective and well-controlled delivery in vivo. Naked RNAs have potential toxicities such as saturation of the innate RNAi machinery, stimulation of the immune response, and off-target effects. Moreover, systemic administration of RNAs encounters several obstacles that reduce their therapeutic efficacy: they are highly unstable intravascularly, with a short half-life due to their susceptibility to serum nucleases and rapid renal clearance. Consequently, RNAs do not accumulate in target tissues and cannot readily cross target cell membranes to access their cytoplasmic site of action. In addition, in the field of viral infections, it is necessary to find out new specific and effective targets and alternative combined targets to avoid mutant escapes.

The efforts to achieve a realistic clinical application of RNAi as therapeutic for viral infections should be focused mainly on three areas: reducing toxicity of RNAs while increasing stability, avoiding mutant escapes, and delivery to target tissues. RNA design and chemical modifications increase stability, reduce immunogenicity, and may help to reduce viral escapes; however, even modified, naked RNAs have poor cellular uptake due to their small size, net negative charge, renal clearance, and hydrophilicity. A range of delivery vectors such as liposomes, polymers, and nanoparticles have been developed to facilitate efficient cellular uptake and target site accumulation as well as to provide a degree of protection. Among all delivery platforms, safe and easily manufactured LNP are good candidates, which can additionally be functionalized to achieve appropriate tropism, especially when the RNAi molecules are not tissue-specific. In addition, the availability of different types of LNP favors the chance of attaining synergistic effects between RNAi molecules and conventional drugs, which may be greatly useful in the case of drugs that develop resistances or do not result effective. All these considerations, joint with data from ongoing clinical trials, suggest that in an early future the delivery of RNAi therapeutics by LNP could be a first-line treatment in several human diseases, such as viral infections.

\section{Conflict of Interests}

The authors declare that there is no conflict of interests regarding the publication of this paper.

\section{Acknowledgment}

This work was supported by the Basque Government's Department of Education, Universities and Investigation (IT341-10).

\section{References}

[1] United States Congress, "Office of Technology Assessment [OTA], Human Gene Therapy-Background Paper," Washington, DC, USA.

[2] Committee for Advanced Therapies (CAT), "Reflection paper on classification of advanced therapy medicinal products," EMA/CAT/600280/2010, 2012.

[3] S. A. Rosenberg, P. Aebersold, K. Cornetta et al., "Gene transfer into humans-immunotherapy of patients with advanced melanoma, using tumor-infiltrating lymphocytes modified by retroviral gene transduction," New England Journal of Medicine, vol. 323, no. 9, pp. 570-578, 1990.

[4] C. Sheridan, "Gene therapy finds its niche," Nature Biotechnology, vol. 29, no. 2, pp. 121-128, 2011.

[5] The Journal of Gene Medicine Clinical Trial site, http://www.abedia.com/wiley/indications.php. 
[6] A. Fire, S. Xu, M. K. Montgomery, S. A. Kostas, S. E. Driver, and C. C. Mello, "Potent and specific genetic interference by doublestranded RNA in caenorhabditis elegans," Nature, vol. 391, no. 6669, pp. 806-811, 1998.

[7] B. Kim, Q. Tang, P. S. Biswas et al., "Inhibition of ocular angiogenesis by siRNA targeting vascular endothelial growth factor pathway genes: therapeutic strategy for herpetic stromal keratitis," The American Journal of Pathology, vol. 165, no. 6, pp. 2177-2185, 2004.

[8] M. S. Weinberg and P. Arbuthnot, "Progress in the use of RNA interference as a therapy for chronic hepatitis B virus infection," Genome Medicine, vol. 2, no. 4, pp. 28-34, 2010.

[9] M. Motavaf, S. Safari, and S. M. Alavian, “Therapeutic potential of RNA interference: a new molecular approach to antiviral treatment for hepatitis C," Journal of Viral Hepatitis, vol. 19, no. 11, pp. 757-765, 2012.

[10] E. Xiaofei, B. M. Stadler, M. Debatis, S. Wang, S. Lu, and T. F. Kowalik, "RNA interference-mediated targeting of human cytomegalovirus immediate-early or early gene products inhibits viral replication with differential effects on cellular functions," Journal of Virology, vol. 86, no. 10, pp. 5660-5673, 2012.

[11] R. Singhania, N. Khairuddin, D. Clarke, and N. A. McMillan, "RNA interference for the treatment of papillomavirus disease," The Open Virology Journal, vol. 6, pp. 204-215, 2012.

[12] D. Vlachakis, G. Tsiliki, A. Pavlopoulou, M. G. Roubelakis, S. Champeris Tsaniras, and S. Kossida, "Antiviral stratagems against HIV-1 using RNA interference (RNAi) technology," Evolutionary Bioinformatics, vol. 9, pp. 203-213, 2013.

[13] T. Betáková and P. Švancarová, "Role and application of RNA interference in replication of influenza viruses," Acta Virologica, vol. 57, no. 2, pp. 97-104, 2013.

[14] D. Ovcharenko, R. Jarvis, S. Hunicke-Smith, K. Kelnar, and D. Brown, "High-throughput RNAi screening "in vitro": from cell lines to primary cells," RNA, vol. 11, no. 6, pp. 985-993, 2005.

[15] V. Dyer, A. Ely, K. Bloom, M. Weinberg, and P. Arbuthnot, "TRNALys3 promoter cassettes that efficiently express RNAiactivating antihepatitis B virus short hairpin RNAs," Biochemical and Biophysical Research Communications, vol. 398, no. 4, pp. 640-646, 2010.

[16] M. Machitani, F. Sakurai, K. Katayama et al., "Improving adenovirus vector-mediated RNAi efficiency by lacking the expression of virus-associated RNAs," Virus Research, vol. 178, no. 2, pp. 357-363, 2013.

[17] T. I. Novobrantseva, A. Borodovsky, J. Wong et al., "Systemic RNAi-mediated gene silencing in nonhuman primate and rodent myeloid cells," Molecular Therapy-Nucleic Acids, vol. 1, article e4, 2012.

[18] H. Arima, A. Yoshimatsu, H. Ikeda et al., "Folate-PEGappended dendrimer conjugate with $\alpha$-cyclodextrin as a novel cancer cell-selective siRNA delivery carrier," Molecular Pharmaceutics, vol. 9, pp. 2591-2604, 2012.

[19] A. R. de Fougerolles, "Delivery vehicles for small interfering RNA in vivo," Human Gene Therapy, vol. 19, no. 2, pp. 125-132, 2008.

[20] K. A. Whitehead, R. Langer, and D. G. Anderson, "Knocking down barriers: advances in siRNA delivery," Nature Reviews Drug Discovery, vol. 8, no. 2, pp. 129-138, 2009.
[21] S. M. Elbashir, W. Lendeckel, and T. Tuschl, "RNA interference is mediated by 21- and 22-nucleotide RNAs," Genes and Development, vol. 15, no. 2, pp. 188-200, 2001.

[22] S. M. Hammond, "Dicing and slicing: the core machinery of the RNA interference pathway," FEBS Letters, vol. 579, no. 26, pp. 5822-5829, 2005.

[23] M. R. Lares, J. J. Rossi, and D. L. Ouellet, "RNAi and small interfering RNAs in human disease therapeutic applications," Trends in Biotechnology, vol. 28, no. 11, pp. 570-579, 2010.

[24] C. B. Moore, E. H. Guthrie, M. T. Huang, and D. J. Taxman, "Short hairpin RNA (shRNA): design, delivery, and assessment of gene knockdown," Methods in Molecular Biology, vol. 629, pp. 141-158, 2010.

[25] Y. Zhang, Z. Wang, and R. A. Gemeinhart, "Progress in microRNA delivery," Journal of Controlled Release, vol. 172, no. 3, pp. 962-974, 2013.

[26] R. J. Taft, K. C. Pang, T. R. Mercer, M. Dinger, and J. S. Mattick, "Non-coding RNAs: regulators of disease," Journal of Pathology, vol. 220, no. 2, pp. 126-139, 2010.

[27] D. D. Rao, J. S. Vorhies, N. Senzer, and J. Nemunaitis, "siRNA versus shRNA: similarities and differences," Advanced Drug Delivery Reviews, vol. 61, no. 9, pp. 746-759, 2009.

[28] P. R. Romano, D. E. McCallus, and C. J. Pachuk, "RNA interference-mediated prevention and therapy for hepatocellular carcinoma," Oncogene, vol. 25, no. 27, pp. 3857-3865, 2006.

[29] D. D. Rao, J. S. Vorhies, N. Senzer, and J. Nemunaitis, "siRNA vs. shRNA: similarities and differences," Advanced Drug Delivery Reviews, vol. 61, no. 9, pp. 746-759, 2009.

[30] R. Triboulet, B. Mari, Y. L. Lin et al., "Suppression of microRNAsilencing pathway by HIV-1 during virus replication," Science, vol. 315, no. 5818, pp. 1579-1582, 2007.

[31] C. Wilkins, R. Dishongh, S. C. Moore, M. A. Whitt, M. Chow, and K. Machaca, "RNA interference is an antiviral defence mechanism in Caenorhabditis elegans," Nature, vol. 436, no. 7053, pp. 1044-1047, 2005.

[32] I. M. Pedersen, G. Cheng, S. Wieland et al., "Interferon modulation of cellular microRNAs as an antiviral mechanism," Nature, vol. 449, no. 7164, pp. 919-922, 2007.

[33] T. Watanabe, T. Umehara, F. Yasui et al., "Liver target delivery of small interfering RNA to the HCV gene by lactosylated cationic liposome," Journal of Hepatology, vol. 47, no. 6, pp. 744-750, 2007.

[34] S. I. Kim, D. Shin, H. Lee, B. Ahn, Y. Yoon, and M. Kim, “Targeted delivery of siRNA against hepatitis $\mathrm{C}$ virus by apolipoprotein A-I-bound cationic liposomes," Journal of Hepatology, vol. 50, no. 3, pp. 479-488, 2009.

[35] H. Lee, S. I. Kim, D. Shin et al., "Hepatic siRNA delivery using recombinant human apolipoprotein A-I in mice," Biochemical and Biophysical Research Communications, vol. 378, no. 2, pp. 192-196, 2009.

[36] P. K. Chandra, A. K. Kundu, S. Hazari et al., "Inhibition of hepatitis $\mathrm{C}$ virus replication by intracellular delivery of multiple siRNAs by nanosomes," Molecular Therapy, vol. 20, no. 9, pp. 1724-1736, 2012.

[37] A. Dallas, H. Ilves, J. Shorenstein, A. Judge, R. Spitler, and C. Conta, "Minimal-length synthetic shRNAs formulated with lipid nanoparticles are potent inhibitors of hepatitis $C$ virus IRES-linked gene expression in mice," Molecular TherapyNucleic Acids, vol. 2, p. e123, 2013. 
[38] L. C. Gomes-da-Silva, N. A. Fonseca, V. Moura, M. C. Pedroso de Lima, S. Simões, and J. N. Moreira, "Lipid-based nanoparticles for siRNA delivery in cancer therapy: paradigms and challenges," Accounts of Chemical Research, vol. 45, no. 7, pp. 1163-1171, 2012.

[39] W. Yu, C. Liu, Y. Liu, N. Zhang, and W. Xu, "Mannan-modified solid lipid nanoparticles for targeted gene delivery to alveolar macrophages," Pharmaceutical Research, vol. 27, no. 8, pp. 15841596, 2010.

[40] J. N. Moreira, A. Santos, V. Moura, M. C. P. de Uma, and S. Simões, "Non-viral lipid-based nanoparticles for targeted cancer systemic gene silencing," Journal of Nanoscience and Nanotechnology, vol. 8, no. 5, pp. 2187-2204, 2008.

[41] A. K. Vaishnaw, J. Gollob, C. Gamba-Vitalo et al., "A status report on RNAi therapeutics," Silence, vol. 1, no. 1, article 14, 2010.

[42] E. Vighi, B. Ruozi, M. Montanari, R. Battini, and E. Leo, "pDNA condensation capacity and in vitro gene delivery properties of cationic solid lipid nanoparticles," International Journal of Pharmaceutics, vol. 389, no. 1-2, pp. 254-261, 2010.

[43] R. Cortesi, M. Campioni, L. Ravani, M. Drechsler, M. Pinotti, and E. Esposito, "Cationic lipid nanosystems as carriers for nucleic acids," New Biotechnology, vol. 31, no. 1, pp. 44-54, 2014.

[44] R. H. Müller, M. Radtke, and S. A. Wissing, "Solid lipid nanoparticles (SLN) and nanostructured lipid carriers (NLC) in cosmetic and dermatological preparations," Advanced Drug Delivery Reviews, vol. 54, supplement 1, pp. S131-S155, 2002.

[45] A. del Pozo-Rodríguez, M. A. Solinís, A. R. Gascón, and J. L. Pedraz, "Short- and long-term stability study of lyophilized solid lipid nanoparticles for gene therapy," European Journal of Pharmaceutics and Biopharmaceutics, vol. 71, no. 2, pp. 181-189, 2009.

[46] A. del Pozo-Rodríguez, D. Delgado, A. R. Gascón, and M. Á. Solinís, "Lipid nanoparticles as drug/gene delivery systems to the retina," Journal of Ocular Pharmacology and Therapeutics, vol. 29, no. 2, pp. 173-188, 2013.

[47] D. V. Morrissey, J. A. Lockridge, L. Shaw et al., "Potent and persistent in vivo anti-HBV activity of chemically modified siRNAs," Nature Biotechnology, vol. 23, no. 8, pp. 1002-1007, 2005.

[48] S. I. Kim, D. Shin, T. H. Choi et al., "Systemic and specific delivery of small interfering RNAs to the liver mediated by apolipoprotein A-I," Molecular Therapy, vol. 15, no. 6, pp. 11451152, 2007.

[49] S. Carmona, M. R. Jorgensen, S. Kolli et al., "Controlling HBV replication in vivo by intravenous administration of triggered PEGylated siRNA-nanoparticles," Molecular Pharmaceutics, vol. 6, no. 3, pp. 706-717, 2009.

[50] M. Mével, N. Kamaly, S. Carmona et al., "DODAG; a versatile new cationic lipid that mediates efficient delivery of pDNA and siRNA," Journal of Controlled Release, vol. 143, no. 2, pp. 222232,2010

[51] J. Hean, C. Crowther, A. Ely et al., "Inhibition of hepatitis B virus replication "in vivo" using lipoplexes containing altritolmodified antiviral siRNAs," Artificial DNA: PNA and XNA, vol. 1, no. 1, pp. 17-26, 2010.

[52] A. Simon, V. Karsten, J. Cehelsky et al., "Results of a phase $2 b$ multi-center trial of ALN-RSV01 in respiratory syncytial virus
(RSV)-infected lung transplant patients," European Respiratory Journal, vol. 40, p. 267s, 2012.

[53] L. F. Gebert, M. A. Rebhan, S. E. Crivelli, R. Denzler, M. Stoffel, and J. Hall, "Miravirsen (SPC3649) can inhibit the biogenesis of miR-122," Nucleic Acids Research, vol. 42, no. 1, pp. 609-621, 2014.

[54] H. L. Janssen, H. W. Reesink, S. Zeuzem et al., "Randomized, double-blind, placebo-controlled safety, anti-viral, proof of concept study of Miravirsen, an oligonucleotide targeting miR122 , in treatment-naive patients with genotype 1 chronic HCV infection," in Proceedings of the Liver Meeting by the AASLD(62nd Annual Meeting), Program Number: LB-6, 2011.

[55] http://www.benitec.com/documents/140529HEPATITISCPATGCOMMENCEDFINAL.pdf.

[56] http://www.arrowheadresearch.com/press-releases/arrowhead -begins-dosing-phase-2a-trial-rnai-therapeutic-arc-520-chronic-hepatitis-b.

[57] 2014, http://www.benitec.com/documents/1311_Calimmune_ Presn_to_SIS.pdf.

[58] Y. C. Tam, S. Chen, and P. R. Cullis, "Advances in lipid nanoparticles for siRNA delivery," Pharmaceutics, vol. 5, no. 3, pp. 498-507, 2013.

[59] H. Mishra, D. Mishra, P. K. Mishra, M. Nahar, V. Dubey, and N. K. Jain, "Evaluation of solid lipid nanoparticles as carriers for delivery of hepatitis b surface antigen for vaccination using subcutaneous route," Journal of Pharmacy and Pharmaceutical Sciences, vol. 13, no. 4, pp. 495-509, 2010.

[60] A. P. Ruiz de Garibay, D. Delgado, A. del Pozo-Rodríguez, M. Á. Solinís, and A. R. Gascón, "Multicomponent nanoparticles as nonviral vectors for the treatment of fabry disease by gene therapy," Drug Design, Development and Therapy, vol. 6, pp. 303-310, 2012.

[61] D. Doroud, A. Vatanara, F. Zahedifard et al., "Cationic solid lipid nanoparticles loaded by cystein proteinase genes as a novel antileishmaniasis DNA vaccine delivery system: characterization and in vitro evaluations.", Journal of Controlled Release, vol. 148, no. 1, pp. e105-e106, 2010.

[62] L. Priano, D. Esposti, R. Esposti et al., "Solid lipid nanoparticles incorporating melatonin as new model for sustained oral and transdermal delivery systems," Journal of Nanoscience and Nanotechnology, vol. 7, no. 10, pp. 3596-3601, 2007.

[63] A. Rodríguez-Gascón, M. Á. Solinís, A. del Pozo-Rodríguez, D. Delgado, and J. L. Pedraz, "Lipid nanoparticles for gene therapy," US 20120183589 Al, 2012.

[64] A. Rodríguez-Gascón, M. Á. Solinís, A. del Pozo-Rodríguez, D. Delgado, and E. Fernández, "Lipid nanoparticles for treating ocular diseases," WO 2012085318 A1, 2012.

[65] A. del Pozo-Rodríguez, S. Pujals, D. Delgado et al., "A proline-rich peptide improves cell transfection of solid lipid nanoparticle-based non-viral vectors," Journal of Controlled Release, vol. 133, no. 1, pp. 52-59, 2009.

[66] D. Delgado, A. Del Pozo-Rodríguez, M. Á. Solinís, and A. Rodríguez-Gascón, "Understanding the mechanism of protamine in solid lipid nanoparticle-based lipofection: the importance of the entry pathway," European Journal of Pharmaceutics and Biopharmaceutics, vol. 79, no. 3, pp. 495-502, 2011.

[67] D. Delgado, A. del Pozo-Rodríguez, M. Á. Solinís, A. Bartkowiak, and A. Rodríguez-Gascón, "New gene delivery 
system based on oligochitosan and solid lipid nanoparticles: "in vitro" and "in vivo" evaluation," European Journal of Pharmaceutical Sciences, vol. 50, no. 3-4, pp. 484-491, 2013.

[68] P. S. Apaolaza, D. Delgado, A. del Pozo-Rodríguez, A. R. Gascón, and M. Á. Solinís, "A novel gene therapy vector based on hyaluronic acid and solid lipid nanoparticles for ocular diseases," International Journal of Pharmaceutics, vol. 465, no. 1-2, pp. 413-426, 2014.

[69] A. del Pozo-Rodríguez, D. Delgado, M. Á. Solinís et al., "Solid lipid nanoparticles as potential tools for gene therapy: "in vivo" protein expression after intravenous administration," International Journal of Pharmaceutics, vol. 385, no. 1-2, pp. 157162, 2010.

[70] D. Delgado, A. R. Gascón, A. del Pozo-Rodrøguez et al., "Dextran-protamine-solid lipid nanoparticles as a non-viral vector for gene therapy: "in vitro" characterization and "in vivo" transfection after intravenous administration to mice," International Journal of Pharmaceutics, vol. 425, no. 1-2, pp. 3543, 2012.

[71] D. Delgado, A. del Pozo-Rodríguez, M. Á. Solinís et al., "Dextran and protamine-based solid lipid nanoparticles as potential vectors for the treatment of X-linked juvenile retinoschisis," Human Gene Therapy, vol. 23, no. 4, pp. 345-355, 2012.

[72] A. del Pozo-Rodríguez, D. Delgado, M. Á. Solinís, and A. R. Gascón, "Lipid nanoparticles as vehicles for macromolecules: nucleic acids and peptides," Recent Patents on Drug Delivery \& Formulation, vol. 5, no. 3, pp. 214-226, 2011.

[73] W. Yu, C. Liu, J. Ye, W. Zou, N. Zhang, and W. Xu, "Novel cationic SLN containing a synthesized single-tailed lipid as a modifier for gene delivery," Nanotechnology, vol. 20, no. 21, Article ID 215102, 2009.

[74] N. Pedersen, S. Hansen, A. V. Heydenreich, H. G. Kristensen, and H. S. Poulsen, "Solid lipid nanoparticles can effectively bind DNA, streptavidin and biotinylated ligands," European Journal of Pharmaceutics and Biopharmaceutics, vol. 62, no. 2, pp. 155162,2006

[75] E. Miele, G. P. Spinelli, E. D. Fabrizio, E. Ferretti, S. Tomao, and A. Gulino, "Nanoparticle-based delivery of small interfering RNA: challenges for cancer therapy," International Journal of Nanomedicine, vol. 7, pp. 3637-3657, 2012.

[76] H. R. Kim, I. K. Kim, K. H. Bae, S. H. Lee, Y. Lee, and T. G. Park, "Cationic solid lipid nanoparticles reconstituted from low density lipoprotein components for delivery of siRNA," Molecular Pharmaceutics, vol. 5, no. 4, pp. 622-631, 2008.

[77] J. Jin, K. H. Bae, H. Yang et al., "In vivo specific delivery of c-Met siRNA to glioblastoma using cationic solid lipid nanoparticles," Bioconjugate Chemistry, vol. 22, no. 12, pp. 2568-2572, 2011.

[78] G. Montana, M. L. Bondì, R. Carrotta et al., "Employment of cationic solid-lipid nanoparticles as RNA carriers," Bioconjugate Chemistry, vol. 18, no. 2, pp. 302-308, 2007.

[79] A. Puri, K. Loomis, B. Smith et al., "Lipid-based nanoparticles as pharmaceutical drug carriers: from concepts to clinic," Critical Reviews in Therapeutic Drug Carrier Systems, vol. 26, no. 6, pp. 523-580, 2009.

[80] S. Das, W. K. Ng, and R. B. H. Tan, "Are nanostructured lipid carriers (NLCs) better than solid lipid nanoparticles (SLNs): development, characterizations and comparative evaluations of clotrimazole-loaded SLNs and NLCs?" European Journal of Pharmaceutical Sciences, vol. 47, no. 1, pp. 139-151, 2012.
[81] C. L. Fang, S. A. Al-Suwayeh, and J. Y. Fang, "Nanostructured lipid carriers (NLCs) for drug delivery and targeting," Recent Patents on Nanotechnology, vol. 7, no. 1, pp. 41-55, 2013.

[82] M. A. Iqbal, S. Md, J. K. Sahni, S. Baboota, S. Dang, and J. Ali, "Nanostructured lipid carriers system: recent advances in drug delivery," Journal of Drug Targeting, vol. 20, no. 10, pp. 813-830, 2012.

[83] A. Beloqui, M. Á. Solinís, A. Delgado, C. Evora, A. Isla, and A. Rodríguez-Gascón, "Fate of nanostructured lipid carriers (NLCs) following the oral route: design, pharmacokinetics and biodistribution," Journal of Microencapsulation, vol. 31, no. 1, pp. $1-8,2014$.

[84] V. Teeranachaideekul, R. H. Müller, and V. B. Junyaprasert, "Encapsulation of ascorbyl palmitate in nanostructured lipid carriers (NLC)-effects of formulation parameters on physicochemical stability," International Journal of Pharmaceutics, vol. 340, no. 1-2, pp. 198-206, 2007.

[85] M. Radtke, E. B. Souto, and R. H. Müller, "Nanostructured lipid carriers: a novel generation of solid lipid drug carriers," Pharmaceutical Technology Europe, vol. 17, no. 4, pp. 45-50, 2005.

[86] M. Joshi, S. Pathak, S. Sharma, and V. Patravale, "Design and in vivo pharmacodynamic evaluation of nanostructured lipid carriers for parenteral delivery of artemether: nanoject," International Journal of Pharmaceutics, vol. 364, no. 1, pp. 119126, 2008.

[87] A. P. Nayak, W. Tiyaboonchai, S. Patankar, B. Madhusudhan, and E. B. Souto, "Curcuminoids-loaded lipid nanoparticles: novel approach towards malaria treatment," Colloids and Surfaces B: Biointerfaces, vol. 81, no. 1, pp. 263-273, 2010.

[88] N. P. Aditya, S. Patankar, B. Madhusudhan, R. S. R. Murthy, and E. B. Souto, "Arthemeter-loaded lipid nanoparticles produced by modified thin-film hydration: pharmacokinetics, toxicological and "in vivo" anti-malarial activity," European Journal of Pharmaceutical Sciences, vol. 40, no. 5, pp. 448-455, 2010.

[89] K. W. Kasongo, J. Pardeike, R. H. Müller, and R. B. Walker, "Selection and characterization of suitable lipid excipients for use in the manufacture of didanosine-loaded solid lipid nanoparticles and nanostructured lipid carriers," Journal of Pharmaceutical Sciences, vol. 100, no. 12, pp. 5185-5196, 2011.

[90] A. Beloqui, M. Á. Solinís, A. R. Gascón, A. del PozoRodríguez, A. des Rieux, and V. Préat, "Mechanism of transport of saquinavir-loaded nanostructured lipid carriers across the intestinal barrier," Journal of Controlled Release, vol. 166, no. 2, pp. 115-123, 2013.

[91] A. Beloqui, M. Á. Solinís, A. des Rieux, V. Préat, and A. Rodríguez-Gascón, "Dextran-protamine coated nanostructured lipid carriers as mucus-penetrating nanoparticles for lipophilic drugs," International Journal of Pharmaceutics, vol. 468, no. 1-2, pp. 105-111, 2014.

[92] O. Taratula, A. Kuzmov, M. Shah, O. B. Garbuzenko, and T. Minko, "Nanostructured lipid carriers as multifunctional nanomedicine platform for pulmonary co-delivery of anticancer drugs and siRNA," Journal of Controlled Release, vol. 71, no. 3, pp. 349-357, 2013.

[93] R. H. Müller and C. Olbrich, "Lipid matrix-drug conjugates particles for controlled release of active ingredient," US6770299, 2004.

[94] R. Paliwal, S. Rai, and S. P. Vyas, "Lipid drug conjugate (LDC) nanoparticles as autolymphotrophs for oral delivery of 
methotrexate," Journal of Biomedical Nanotechnology, vol. 7, no. 1, pp. 130-131, 2011.

[95] P. Sharma, B. Dube, and K. Sawant, "Synthesis of cytarabine lipid drug conjugate for treatment of meningeal leukemia: development, characterization and in vitro cell line studies," Journal of Biomedical Nanotechnology, vol. 8, no. 6, pp. 928-937, 2012.

[96] C. Olbrich, A. Gessner, O. Kayser, and R. H. Müller, "Lipiddrug-conjugate (LDC) nanoparticles as novel carrier system for the hydrophilic antitrypanosomal drug diminazenediaceturate," Journal of Drug Targeting, vol. 10, no. 5, pp. 387-396, 2002.

[97] C. Olbrich, A. Gessner, W. Schröder, O. Kayser, and R. H. Müller, "Lipid-drug conjugate nanoparticles of the hydrophilic drug diminazene-cytotoxicity testing and mouse serum adsorption," Journal of Controlled Release, vol. 96, no. 3, pp. 425435, 2004.

[98] D. Liu, "Recent advances in myelodysplasia: update from 2011 ASH annual meeting," Journal of Hematology \& Oncology, vol. 5, supplement 1, p. A4, 2012.

[99] Y. R. Neupane, M. D. Sabir, N. Ahmad, M. Ali, and K. Kohli, "Lipid drug conjugate nanoparticle as a novel lipid nanocarrier for the oral delivery of decitabine : "ex vivo" gut permeation studies," Nanotechnology, vol. 24, no. 41, Article ID 415102, 2013.

[100] L. M. Verissimo, L. F. Agnez Lima, L. C. Monte Egito, A. G. de Oliveira, and E. S. T. do Egito, "Pharmaceutical emulsions: a new approach for gene therapy," Journal of Drug Targeting, vol. 18 , no. 5, pp. 333-342, 2010.

[101] S. W. Yi, T. Y. Yune, T. W. Kim et al., "A cationic lipid emulsion/DNA complex as a physically stable and serumresistant gene delivery system," Pharmaceutical Research, vol. 17, no. 3, pp. 314-320, 2000.

[102] H. S. Yoo, O. Mazda, H. Y. Lee et al., "In vivo gene therapy of type I diabetic mellitus using a cationic emulsion containing an Epstein Barr Virus (EBV) based plasmid vector," Journal of Controlled Release, vol. 112, no. 1, pp. 139-144, 2006.

[103] M. M. Kaneda, Y. Sasaki, G. M. Lanza, J. Milbrandt, and S. A. Wickline, "Mechanisms of nucleotide trafficking during siRNA delivery to endothelial cells using perfluorocarbon nanoemulsions," Biomaterials, vol. 31, no. 11, pp. 3079-3086, 2010.

[104] A. Rodríguez-Gascón, A. del Pozo-Rodríguez, and M. Á. Solinís, "Development of nucleic acid vaccines: use of selfamplifying RNA in lipid nanoparticles," International Journal of Nanomedicine, vol. 9, no. 1, pp. 1833-1843, 2014.

[105] K. Gavrilov and W. M. Saltzman, "Therapeutic siRNA: principles, challenges, and strategies," Yale Journal of Biology and Medicine, vol. 85, no. 2, pp. 187-200, 2012.

[106] C. N. Landen Jr., A. Chavez-Reyes, C. Bucana et al., “Therapeutic EphA2 gene targeting in vivo using neutral liposomal small interfering RNA delivery," Cancer Research, vol. 65, no. 15, pp. 6910-6918, 2005.

[107] C. Zhang, N. Tang, X. Liu, W. Liang, W. Xu, and V. P. Torchilin, "siRNA-containing liposomes modified with polyarginine effectively silence the targeted gene," Journal of Controlled Release, vol. 112, no. 2, pp. 229-239, 2006.

[108] S. M. Kwon, H. Y. Nam, T. Nam et al., "In vivo time-dependent gene expression of cationic lipid-based emulsion as a stable and biocompatible non-viral gene carrier," Journal of Controlled Release, vol. 128, no. 1, pp. 89-97, 2008.
[109] Z. Hyvönen, S. Rönkkö, M.R. Toppinen, I. Jääskeäinen, A. Plotniece, and A. Urtti, "Dioleoyl phosphatidylethnolamine and PEG-lipid conjugates modify DNA delivery medicated by 1 , 4-dihydropyridine amphiphiles," Journal of Controlled Release, vol. 99, no. 1, pp. 177-190, 2004.

[110] L. Deng, Y. Zhang, L. Ma et al., "Comparison of anti-EGFR$\mathrm{Fab} /$ conjugated immunoliposomes modified with two different conjugation linkers for siRNA delivery in SMMC-7721 cells," International Journal of Nanomedicine, vol. 8, pp. 3271-3283, 2013.

[111] S. Kim, D. Peer, P. Kumar et al., "RNAi-mediated CCR5 silencing by LFA-1-targeted nanoparticles prevents HIV infection in BLT mice," Molecular Therapy, vol. 18, no. 2, pp. 370-376, 2010.

[112] Q. Pan, H. W. Tilanus, H. L. A. Janssen, and L. J. W. Van Der Laan, "Prospects of RNAi and microRNA-based therapies for hepatitis C," Expert Opinion on Biological Therapy, vol. 9, no. 6, pp. 713-724, 2009.

[113] J. M. Luke, G. G. Simon, J. Söderholm et al., "Coexpressed RIG-I agonist enhances humoral immune response to influenza virus DNA vaccine," Journal of Virology, vol. 85, no. 3, pp. 1370-1383, 2011.

[114] Hepatitis C Fact sheet No 164, http://www.who.int/mediacentre/factsheets/fs164/en/.

[115] H. J. Hnatyszyn, "Chronic hepatitis C and genotyping: The clinical significance of determining HCV genotypes," Antiviral Therapy, vol. 10, no. 1, pp. 1-11, 2005.

[116] C. Park, S. Jiang, and K. A. Lawson, "Efficacy and safety of telaprevir and boceprevir in patients with hepatitis $\mathrm{C}$ genotype 1: a meta-analysis," Journal of Clinical Pharmacy and Therapeutics, vol. 39, no. 1, pp. 14-24, 2014.

[117] Y. Takigawa, M. Nagano-Fujii, L. Deng et al., "Suppression of hepatitis $\mathrm{C}$ virus replicon by RNA interference directed against the NS3 and NS5B regions of the viral genome," Microbiology and Immunology, vol. 48, no. 8, pp. 591-598, 2004.

[118] R. Prabhu, P. Vittal, Q. Yin et al., "Small interfering RNA effectively inhibits protein expression and negative strand RNA synthesis from a full-length hepatitis C virus clone," Journal of Medical Virology, vol. 76, no. 4, pp. 511-519, 2005.

[119] M. Kim, D. Shin, S. I. Kim, and M. Park, "Inhibition of hepatitis $\mathrm{C}$ virus gene expression by small interfering RNAs using a tri-cistronic full-length viral replicon and a transient mouse model," Virus Research, vol. 122, no. 1-2, pp. 1-10, 2006.

[120] R. Prabhu, R. F. Garry, and S. Dash, "Small interfering RNA targeted to stem-loop II of the $5 /$ untranslated region effectively inhibits expression of six HCV genotypes," Virology Journal, vol. 3, article 100, 2006.

[121] T. Yokota, N. Sakamoto, N. Enomoto et al., "Inhibition of intracellular hepatitis $C$ virus replication by synthetic and vector-derived small interferring RNAs," EMBO Reports, vol. 4, no. 6, pp. 602-608, 2003.

[122] T. Kanda, R. Steele, R. Ray, and R. B. Ray, "Small interfering RNA targeted to hepatitis C virus $5 /$ nontranslated region exerts potent antiviral effect," Journal of Virology, vol. 81, no. 2, pp. 669-676, 2007.

[123] A. R. N. Zekri, A. A. Bahnassy, H. M. A. El-Din, and H. M. Salama, "Consensus siRNA for inhibition of HCV genotype-4 replication,” Virology Journal, vol. 6, article 13, 2009. 
[124] R. B. Ray and T. Kanda, "Inhibition of HCV replication by small interfering RNA," Methods in Molecular Biology, vol. 510, pp. 251-262, 2009.

[125] R. de Francesco and G. Migliaccio, "Challenges and successes in developing new therapies for hepatitis C," Nature, vol. 436, no. 7053, pp. 953-960, 2005.

[126] L. Zender, S. Hütker, C. Liedtke et al., "Caspase 8 small interfering RNA prevents acute liver failure in mice," Proceedings of the National Academy of Sciences of the United States of America, vol. 100, no. 13, pp. 7797-7802, 2003.

[127] S. D. Henry, P. van der Wegen, H. J. Metselaar, H. W. Tilanus, B. J. Scholte, and L. J. W. van der Laan, "Simultaneous targeting of HCV replication and viral binding with a single lentiviral vector containing multiple RNA interference expression cassettes," Molecular Therapy, vol. 14, no. 4, pp. 485-493, 2006.

[128] A. K. Kundu, P. K. Chandra, S. Hazari, Y. V. Pramar, S. Dash, and T. K. Mandal, "Development and optimization of nanosomal formulations for siRNA delivery to the liver," European Journal of Pharmaceutics and Biopharmaceutics, vol. 80, no. 2, pp. 257267, 2012.

[129] D. Ivacik, A. Ely, and P. Arbuthnot, "Countering hepatitis B virus infection using RNAi: How far are we from the clinic?" Reviews in Medical Virology, vol. 21, no. 6, pp. 383-396, 2011.

[130] B. Hepatitis, Fact sheet No. 204, 2013, http://www.who.int/ mediacentre/factsheets/fs204/en/.

[131] E. B. Keeffe, D. T. Dieterich, J. Pawlotsky, and Y. Benhamou, "Chronic hepatitis B: preventing, detecting, and managing viral resistance," Clinical Gastroenterology and Hepatology, vol. 6, no. 3, pp. 268-274, 2008.

[132] F. Zoulim, "Hepatitis B virus resistance to antiviral drugs: where are we going?” Liver International, vol. 31, supplement 1, pp. 111116, 2011.

[133] W. Jiang, "Blockade of B7-H1 enhances dendritic cell-mediated $\mathrm{T}$ cell response and antiviral immunity in $\mathrm{HBV}$ transgenic mice," Vaccine, vol. 30, no. 4, pp. 758-766, 2012.

[134] C. I. Wooddell, D. B. Rozema, M. Hossbach et al., "Hepatocytetargeted RNAi therapeutics for the treatment of chronic hepatitis B virus infection," Molecular Therapy, vol. 21, no. 5, pp. 973985, 2013.

[135] A. Shlomai and Y. Shaul, "Inhibition of hepatitis B virus expression and replication by RNA interference," Hepatology, vol. 37, no. 4, pp. 764-770, 2003.

[136] S. L. Uprichard, B. Boyd, A. Althage, and F. V. Chisari, "Clearance of hepatitis B virus from the liver of transgenic mice by short hairpin RNAs," Proceedings of the National Academy of Sciences of the United States of America, vol. 102, no. 3, pp. 773$778,2005$.

[137] S. Carmona, A. Ely, C. Crowther et al., "Effective inhibition of HBV replication in vivo by anti-HBx short hairpin RNAs," Molecular Therapy, vol. 13, no. 2, pp. 411-421, 2006.

[138] D. Sun, C. Rösler, K. Kidd-Ljunggren, and M. Nassal, "Quantitative assessment of the antiviral potencies of 21 shRNA vectors targeting conserved, including structured, hepatitis B virus sites," Hepatology, vol. 52, no. 6, pp. 817-826, 2010.

[139] F. He, E. Chen, L. Liu et al., "Inhibition of hepatitis B Virus replication by hepatocyte nuclear factor 4-alpha specific short hairpin RNA," Liver International, vol. 32, no. 5, pp. 742-751, 2012.
[140] X. J. Wang, Y. Li, H. Huang et al., "A simple and robust vectorbased shRNA expression system used for RNA interference," PLoS ONE, vol. 8, no. 2, Article ID e56110, 2013.

[141] H. Giladi, M. Ketzinel-Gilad, L. Rivkin, Y. Felig, O. Nussbaum, and E. Galun, "Small interfering RNA inhibits hepatitis B virus replication in mice," Molecular Therapy, vol. 8, no. 5, pp. 769776, 2003.

[142] M. D. Moore, M. J. McGarvey, R. A. Russell, B. R. Cullen, and M. O. McClure, "Stable inhibition of hepatitis B virus proteins by small interfering RNA expressed from viral vectors," Journal of Gene Medicine, vol. 7, no. 7, pp. 918-925, 2005.

[143] K. Wu, X. Zhang, J. Zhang et al., "Inhibition of Hepatitis B virus gene expression by single and dual small interfering RNA treatment," Virus Research, vol. 112, no. 1-2, pp. 100-107, 2005.

[144] M. D. Marimani, A. Ely, M. C. R. Buff, S. Bernhardt, J. W. Engels, and P. Arbuthnot, "Inhibition of hepatitis B virus replication in cultured cells and in vivo using $2 /$-O-guanidinopropyl modified siRNAs," Bioorganic and Medicinal Chemistry, vol. 21, no. 20, pp. 6145-6155, 2013.

[145] E. Ambegia, S. Ansell, P. Cullis, J. Heyes, L. Palmer, and I. MacLachlan, "Stabilized plasmid-lipid particles containing PEG-diacylglycerols exhibit extended circulation lifetimes and tumor selective gene expression," Biochimica et Biophysica Acta: Biomembranes, vol. 1669, no. 2, pp. 155-163, 2005.

[146] HIV/AIDS Fact sheet No.360, 2013, http://www.who.int/mediacentre/factsheets/fs360/en.

[147] N. S. Lee, T. Dohjima, G. Bauer et al., "Expression of small interfering RNAs targeted against HIV-1 rev transcripts in human cells," Nature Biotechnology, vol. 20, no. 5, pp. 500-505, 2002.

[148] Y. Naito, K. Nohtomi, T. Onogi et al., "Optimal design and validation of antiviral siRNA for targeting HIV-1," Retrovirology, vol. 4, article 80, 2007.

[149] O. ter Brake, N. Legrand, K. J. von Eije et al. et al., "Evaluation of safety and efficacy of RNAi against HIV-1 in the human immune system (Rag-2(-/-)gammac(-/-)) mouse model," Gene Therapy, vol. 16, no. 1, pp. 148-153, 2009.

[150] D. S. An, R. E. Donahue, M. Kamata et al., "Stable reduction of CCR 5 by RNAi through hematopoietic stem cell transplant in non-human primates," Proceedings of the National Academy of Sciences of the United States of America, vol. 104, no. 32, pp. 13110-13115, 2007.

[151] J. S. Anderson, J. Walker, J. A. Nolta, and G. Bauer, "Specific transduction of hiv-susceptible cells for CCR5 knockdown and resistance to HIV infection: a novel method for targeted gene therapy and intracellular immunization," Journal of Acquired Immune Deficiency Syndromes, vol. 52, no. 2, pp. 152-161, 2009.

[152] F. Boutimah, J. J. M. Eekels, Y. P. Liu, and B. Berkhout, "Antiviral strategies combining antiretroviral drugs with RNAi-mediated attack on HIV-1 and cellular co-factors," Antiviral Research, vol. 98, no. 1, pp. 121-129, 2013.

[153] R. G. Amado, R. T. Mitsuyasu, J. D. Rosenblatt et al., "Antihuman immunodeficiency virus hematopoietic progenitor celldelivered ribozyme in a phase I study: myeloid and lymphoid reconstitution in human immunodeficiency virus type-1infected patients," Human Gene Therapy, vol. 15, no. 3, pp. 251$262,2004$.

[154] B. L. Levine, L. M. Humeau, J. Boyer et al., "Gene transfer in humans using a conditionally replicating lentiviral vector," 
Proceedings of the National Academy of Sciences of the United States of America, vol. 103, no. 46, pp. 17372-17377, 2006.

[155] D. L. DiGiusto, A. Krishnan, L. Li et al., "RNA-based gene therapy for HIV with lentiviral vector-modified $\mathrm{CD}^{+} 4^{+}$cells in patients undergoing transplantation for AIDS-related lymphoma," Science Translational Medicine, vol. 2, no. 36, pp. 36-43, 2010.

[156] S. J. Zeller and P. Kumar, "RNA-based Gene therapy for the treatment and prevention of HIV: from bench to bedside," The Yale Journal of Biology and Medicine, vol. 84, no. 3, pp. 301-309, 2011.

[157] X. Lu, Q. Yu, G. K. Binder et al., "Antisense-mediated inhibition of human immunodeficiency virus (HIV) replication by use of an HIV type 1-based vector results in severely attenuated mutants incapable of developing resistance," Journal of Virology, vol. 78, no. 13, pp. 7079-7088, 2004.

[158] O. ter Brake, P. Konstantinova, M. Ceylan, and B. Berkhout, "Silencing of HIV-1 with RNA interference: a multiple shRNA approach," Molecular Therapy, vol. 14, no. 6, pp. 883-892, 2006.

[159] P. Kumar, H. Ban, S. Kim et al., "T cell-specific siRNA delivery suppresses HIV-1 infection in humanized mice," Cell, vol. 134, no. 4, pp. 577-586, 2008.

[160] Y. P. Liu, J. Haasnoot, O. ter Brake, B. Berkhout, and P. Konstantinova, "Inhibition of HIV-1 by multiple siRNAs expressed from a single microRNA polycistron," Nucleic Acids Research, vol. 36, no. 9, pp. 2811-2824, 2008.

[161] J. R. Greenland, R. Geiben, S. Ghosh, W. A. Pastor, and N. L. Letvin, "Plasmid DNA vaccine-elicited cellular immune responses limit in vivo vaccine antigen expression through Fasmediated apoptosis," Journal of Immunology, vol. 178, no. 9, pp. 5652-5658, 2007.

[162] R. Geiben-Lynn, K. Frimpong-Boateng, and N. L. Letvin, "Modulation of plasmid DNA vaccine antigen clearance by caspase 12 RNA interference potentiates vaccination," Clinical and Vaccine Immunology, vol. 18, no. 4, pp. 533-538, 2011.

[163] L. A. Wheeler, R. Trifonova, V. Vrbanac et al., "Inhibition of HIV transmission in human cervicovaginal explants and humanized mice using CD4 aptamer-siRNA chimeras," Journal of Clinical Investigation, vol. 121, no. 6, pp. 2401-2412, 2011.

[164] Z. Cui, J. Patel, M. Tuzova et al., "Strong T cell type-1 immune responses to HIV-1 Tat (1-72) protein-coated nanoparticles," Vaccine, vol. 22, no. 20, pp. 2631-2640, 2004.

[165] J. Patel, D. Galey, J. Jones et al., "HIV-1 Tat-coated nanoparticles result in enhanced humoral immune responses and neutralizing antibodies compared to alum adjuvant," Vaccine, vol. 24, no. 17, pp. 3564-3573, 2006.

[166] M. A. Arias, A. Loxley, C. Eatmon et al., "Carnauba wax nanoparticles enhance strong systemic and mucosal cellular and humoral immune responses to HIV-gp140 antigen," Vaccine, vol. 29, no. 6, pp. 1258-1269, 2011.

[167] D. Palliser, D. Chowdhury, Q. Wang et al., "An siRNA-based microbicide protects mice from lethal herpes simplex virus 2 infection," Nature, vol. 439, no. 7072, pp. 89-94, 2006.

[168] Y. Wu, F. Navarro, A. Lal et al., "Durable protection from Herpes Simplex Virus-2 transmission following intravaginal application of siRNAs targeting both a viral and host gene," Cell Host and Microbe, vol. 5, no. 1, pp. 84-94, 2009.

[169] T. W. Geisbert, L. E. Hensley, E. Kagan et al., "Postexposure protection of guinea pigs against a lethal ebola virus challenge is conferred by RNA interference," Journal of Infectious Diseases, vol. 193, no. 12, pp. 1650-1657, 2006.

[170] T. W. Geisbert, A. C. Lee, M. Robbins et al., "Postexposure protection of non-human primates against a lethal Ebola virus challenge with RNA interference: a proof-of-concept study," The Lancet, vol. 375, no. 9729, pp. 1896-1905, 2010.

[171] X. Z. Chen, K. J. Zhu, Y. Xu et al., "RNA interference silences the human papillomavirus 6b/11 early gene E7 in vitro and in vivo," Clinical and Experimental Dermatology, vol. 35, no. 5, pp. 509-515, 2010.

[172] Y. J. Yang, P. S. Zhao, T. Zhang et al., "Small interfering RNAs targeting the rabies virus nucleoprotein gene," Virus Research, vol. 169, no. 1, pp. 169-174, 2012.

[173] K. Khantasup, P. Kopermsub, K. Chaichoun, and T. Dharakul, "Targeted small interfering RNA-immunoliposomes as a promising therapeutic agent against highly pathogenic Avian Influenza A (H5N1) virus infection," Antimicrobial Agents and Chemotherapy, vol. 58, no. 5, pp. 2816-2824, 2014.

[174] A. J. Geall, A. Verma, G. R. Otten et al., "Nonviral delivery of self-amplifying RNA vaccines," Proceedings of the National Academy of Sciences of the United States of America, vol. 109, no. 36, pp. 14604-14609, 2012.

[175] S. J. Blake, F. F. Bokhari, and N. A. McMillan, "RNA interference for viral infections," Current Drug Targets, vol. 13, no. 11, pp. 1411-1420, 2012.

[176] J. DeVincenzo, R. Lambkin-Williams, T. Wilkinson et al., "A randomized, double-blind, placebo-controlled study of an RNAi-based therapy directed against respiratory syncytial virus," Proceedings of the National Academy of Sciences of the United States of America, vol. 107, no. 19, pp. 8800-8805, 2010.

[177] R. Kanasty, J. R. Dorkin, A. Vegas, and D. Anderson, "Current prospects for RNA interference-based therapies and delivery materials for siRNA therapeutics," Nature Materials, vol. 12, pp. 967-977, 2013.

[178] T. Schluep, L. Kalinoski, C. Wooddell, D. Lewis, R. Gish, and J. Lickliter, "A Phase I, first in human clinical trial of ARC520, an siRNA-based therapeutic for the treatment of chronic hepatitis B virus infection, in normal healthy volunteers," Global Antiviral Journal, vol. 9, suplement 2, p. 57, 2013, HEP DART. 

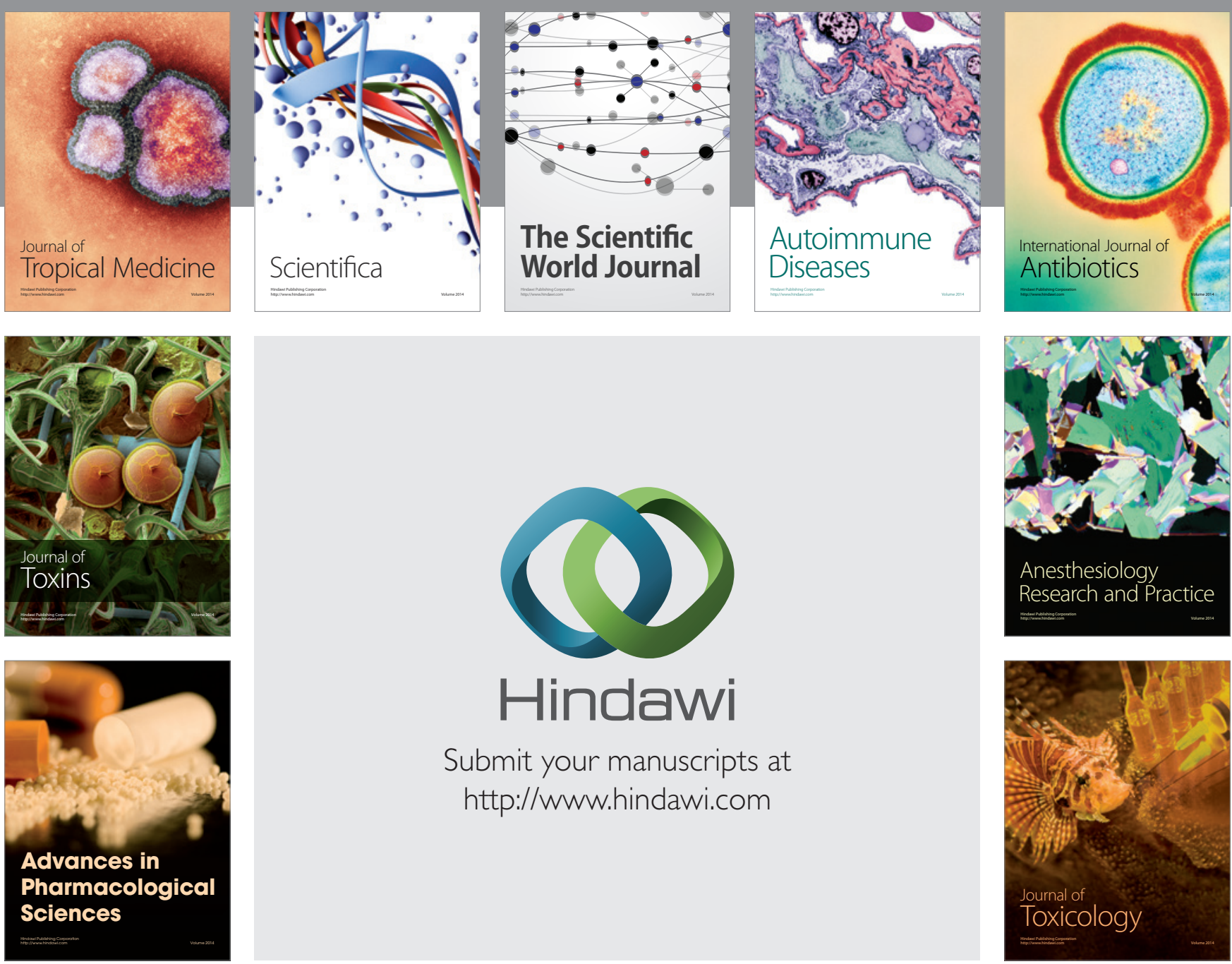

\section{Hindawi}

Submit your manuscripts at

http://www.hindawi.com
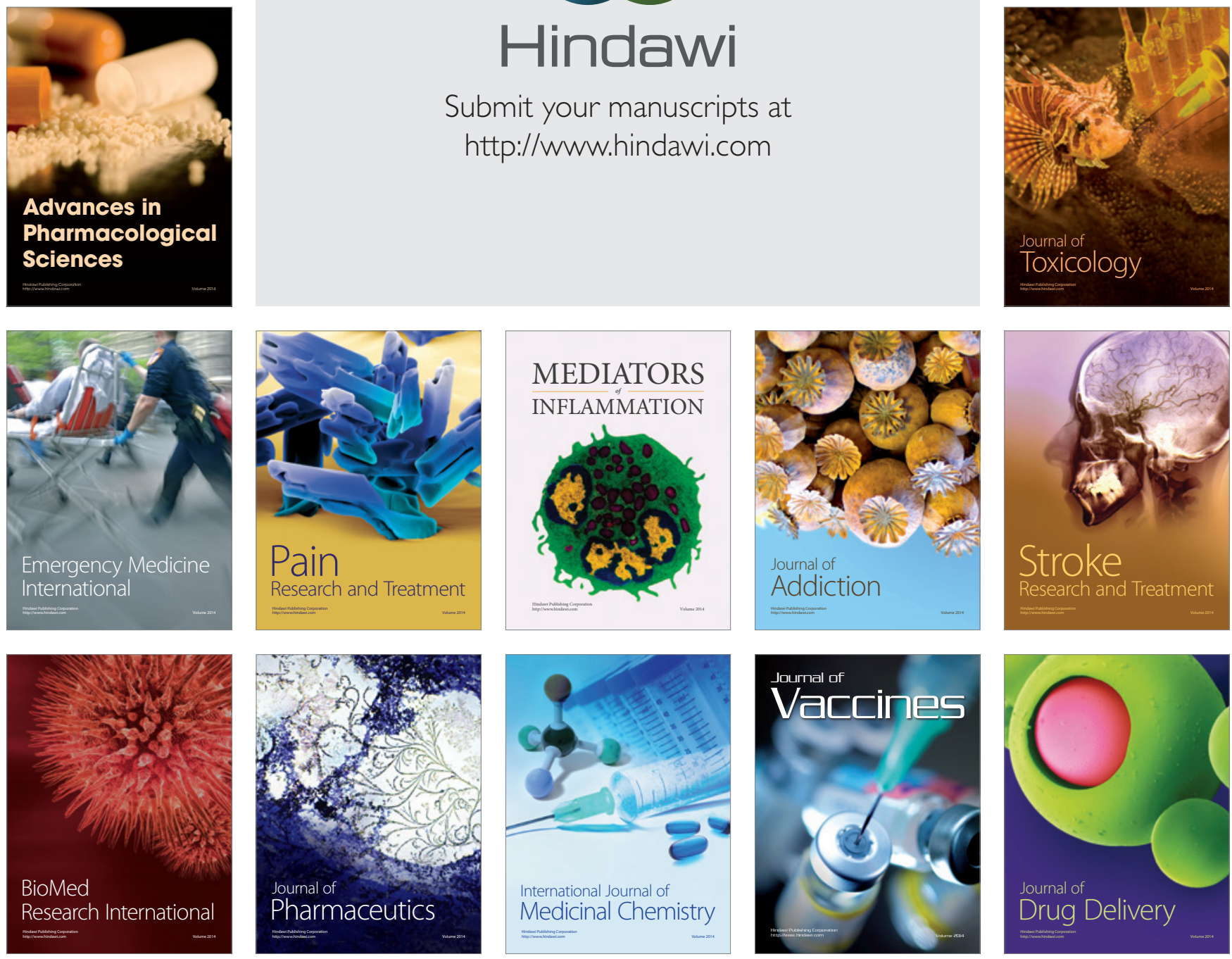